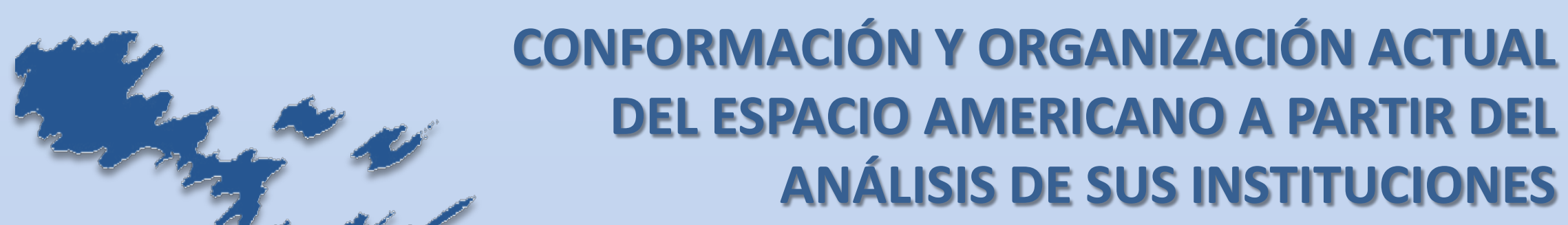

MATERIAL DE CONSULTA DE CÁTEDRA ELABORADO A PARTIR DE LA COMPILACIÓN DE BIBLIOGRAFÍA IMPRESA Y DE INTERNET $x$
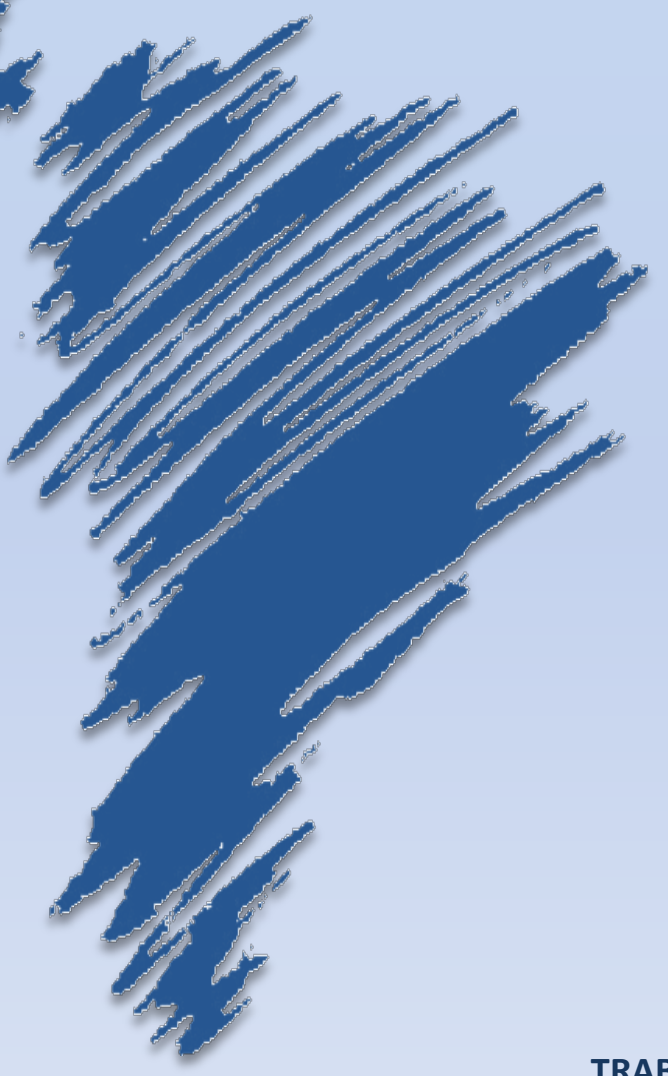

PROFESORADO Y LICENCIATURA EN GEOGRAFÍA

Dr. Prof. Aníbal M. Mignone Dr. Prof. Jorge A. Alberto Prof. Alejandra Torre Geraldi Geografía de América Geografía Argentina

PROFESORADO Y LICENCIATURA EN HISTORÍA

Dr. Prof. Mabel Novoa

Mg. Prof. María Russo

Historia de América Independiente

TRABAJO PRESENTADO EN EL SEMINARIO INTERDISCIPLINARIO:

"Estudio de la conformación y organización actual del espacio americano a partir del análisis de sus instituciones desde la perspectiva histórica y geográfica". Facultad de Humanidades, Universidad Nacional del Nordeste, 14 y 21 de octubre de 2016

Publicado en formato digital: Aníbal Marcelo Mignone, Jorge Alfredo Alberto, Alejandra Torre Geraldi, Mabel Novoa, María Russo. CONFORMACIÓN Y ORGANIZACIÓN ACTUAL DEL ESPACIO AMERICANO A PARTIR DEL ANÁLISIS DE SUS INSTITUCIONES. Revista Geográfica Digital. IGUNNE. Facultad de Humanidades. UNNE. Año 14. № 26. Enero - Junio 2017. ISSN 1668- 5180 Resistencia, Chaco. En: http://hum.unne.edu.ar/revistas/geoweb/default.htm 
Esta presentación forma parte de la exposición resumida de un trabajo presentado en el Seminario Interdisciplinario “Estudio de la conformación y organización actual del espacio americano a partir del análisis de sus instituciones desde la perspectiva histórica y geográfica". Resolución n²63/16 CD. Facultad de Humanidades, Universidad Nacional del Nordeste, 14 y 21 de octubre de 2016 .

\section{Ente Organizador:}

Cátedras:

- Historia de América Independiente (Profesorado y Licenciatura en Historia - Departamento de Historia)

- Geografía de América (Profesorado y Licenciatura en Geografía - Departamento de Geografía)

- Geografía de Argentina (Profesorado y Licenciatura en Geografía - Departamento de Geografía)

\section{Docentes: Dra. Prof. Silvia Mabel Novoa}

Mgtr. Prof. Elena Russo de Pagno

Dr. Prof. Jorge Alfredo Alberto

Dr. Prof. Marcelo Aníbal Mignone

Prof. Alejandra Torre Geraldi

\section{Objetivo:}

Los profesores de las cátedras antedichas de los Departamentos de Historia y de Geografía, que integran áreas similares en carreras distintas pero con el mismo objetivo de conocer la realidad Americana, propician esta actividad como una posibilidad de inserción de temáticas propias de cada disciplina permitiendo la visualización de la interrelación entre procesos históricos y hechos geográficos que se producen, en el tiempo y el espacio, en el continente americano.

Titulo:

Conformación y organización actual del espacio americano a partir del análisis de sus instituciones.

Autor/es:

Dr. Prof. Marcelo Aníbal Mignone, animarmig@hotmail.com

Dr. Prof. Alberto, Jorge Alfredo, jaalberto@hotmail.com,

Dra. Prof. Silvia Mabel Novoa

Prof. Alejandra Torre Geraldi

Mgtr. Prof. Elena Russo de Pagno

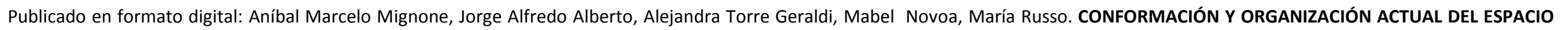

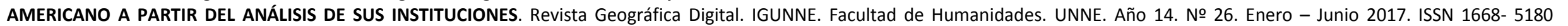
Resistencia, Chaco. En: http://hum.unne.edu.ar/revistas/geoweb/default.htm 


\section{OBJETIVO DEL ARTÍCULO}

El objetivo de este trabajo, basado en la compulsa y síntesis de materiales impresos y de internet, consiste en brindar a los alumnos de la carrera de Geografía e Historia conceptos introductorios referidos a la dinámica socio económica del continente americano.

Se pretende, por un lado, que se reconozcan y comprendan los procesos históricos que intervienen en las actividades políticas, económicas y sociales del continente y las relaciones dinámicas que se establecen entre ellos, y por otro, que se identifiquen y entiendan las dimensiones temporales y espaciales propias de los hechos socioeconómicos que caracterizan el espacio geográfico presente.

La presentación se encuentra organizada en tres momentos de trabajo que se detallan a continuación:

El primero hace referencia, de manera introductoria, al alcance de los conceptos de territorio, estado y nación brindado por diferentes autores y de manera comparativa, a los conceptos de limite y frontera, centrando su atención en la implicancia del concepto de frontera móvil.

El segundo trabaja sobre hechos y procesos históricos significativos en América en donde se analiza la evolución de diferentes conflictos armados (Guerra de la Secesión, la Guerra del Salitre, la Guerra del Chaco) y la presencia de la National Fruit Company, con especial énfasis en las condiciones políticas e intereses económicos presentes.

El tercero, se centra en la caracterización a partir de una síntesis analítica y comparativa en relación a los procesos y condicionantes socioeconómicos de las fronteras en cuatro estudios de caso: Frontera Estados Unidos - México

$$
\begin{aligned}
& \text { Frontera Colombo - Venezolana } \\
& \text { Frontera Colombo - Ecuatoriana } \\
& \text { Triple Frontera Argentina - Brasil - Paraguay }
\end{aligned}
$$

Publicado en formato digital: Aníbal Marcelo Mignone, Jorge Alfredo Alberto, Alejandra Torre Geraldi, Mabel Novoa, María Russo. CONFORMACIÓN Y ORGANIZACIÓN ACTUAL DEL ESPACIO AMERICANO A PARTIR DEL ANÁLISIS DE SUS INSTITUCIONES. Revista Geográfica Digital. IGUNNE. Facultad de Humanidades. UNNE. Año 14. № 26. Enero - Junio 2017. ISSN 1668- 5180 Resistencia, Chaco. En: http://hum.unne.edu.ar/revistas/geoweb/default.htm 


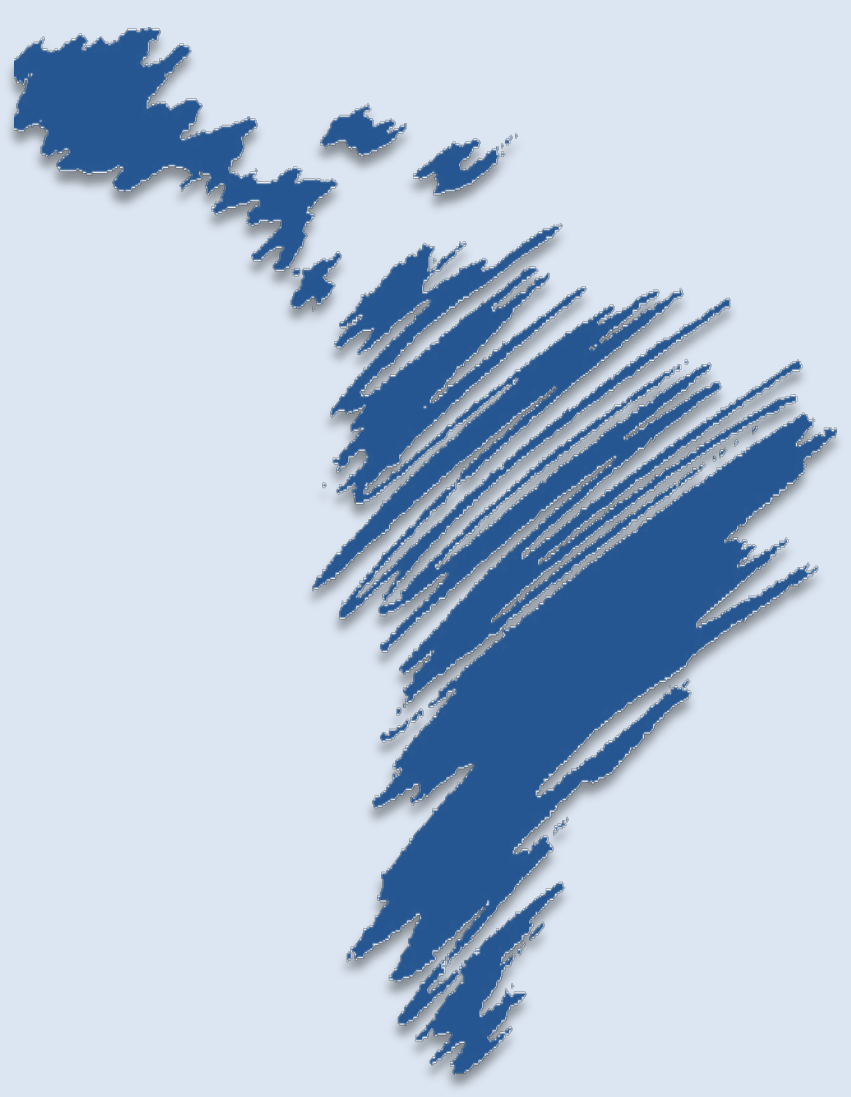

\section{APROXIMACIONES CONCEPTUALES}




\section{ALCANCES DEL CONCEPTO TERRITORIO}

- "Porción de la superficie terrestre perteneciente a un Estado, región,....etc." (Real Academia Española).

- "Parcela geográfica que sirve de hábitat exclusivo a un grupo humano" .... (Del Campo, 1976). Exclusivo porque el individuo o grupo tiende a mantener su derecho a habitar.

- Hay un sentido de propiedad territorial por parte de la sociedad que se va agudizando con el devenir histórico.
- Territorio posee cierto grado de inmutabilidad y de perdurabilidad, tanto para los pobladores como para los habitantes de otros estados (es real).

- Territorio indica la tierra dónde están sepultados nuestros ancestros, nomina la tierra en que vivimos, otorga una nacionalidad, integra el concepto de patria.

- Territorio como espacio apropiado.

- Territorio como ámbito de ejercicio del dominio y control. 


\section{ALCANCES DEL CONCEPTO NACIÓN}

- Conjunto de personas que pertenecen a una misma etnia, que hablan la misma lengua, que profesan la misma religión y que poseen un pasado común, que se trasunta en su vida cultural (costumbres, forma de vestir, idiosincrasia, etc.).

- No constituyen en forma exclusiva el pueblo de un estado particular sino que integran parcialmente numerosos pueblos Ejemplo: "nación gitana".

- Nación es equivalente a Pueblo cuando el pueblo de un estado es lo suficientemente homogéneo para permitir la sinonimia. Ejemplo : "nación francesa".

- Confusión al tratar Nación como sinónimo de Estado, porque un estado puede estar formado por varias naciones. Ejemplo: ex URSS, ex Yugoslavia. 


\section{ALCANCES DEL CONCEPTO ESTADO}

- El "Estado Nacional" puede considerarse como manifestación de que existe una evidente amalgama entre los elementos que constituyen un Estado, que es el resultado de una larga maduración histórica (Sanguin 1981).

- Un estado debe lograr el reconocimiento de su existencia por parte de los restantes estados nacionales.

- La comunidad internacional acepta que ese estado tiene soberanía sobre una porción de la superficie terrestre.

- La soberanía es: la capacidad de todo estado de tomar decisiones sobre el territorio y la población que gobierna, sin que interfiera otro estado. 
COMPARACIÓN DE LOS CONCEPTOS DE LÍMITE Y FRONTERA

\begin{tabular}{|l|l|l|}
\hline \multicolumn{1}{|c|}{ Ítem } & \multicolumn{1}{|c|}{ Límite Internacional } & \multicolumn{1}{|c|}{ Frontera } \\
\hline Existencia & $\begin{array}{l}\text { Ente abstracto de existencia } \\
\text { jurídica. Marca el confín del } \\
\text { Estado. }\end{array}$ & $\begin{array}{l}\text { Hecho real. Es un sector del territorio } \\
\text { nacional; es la epidermis del Estado. }\end{array}$ \\
\hline Expresión & $\begin{array}{l}\text { Por medio de hitos y otros } \\
\text { elementos (barreras, alambrados, } \\
\text { etc.) }\end{array}$ & $\begin{array}{l}\text { Por medio de hechos propios de la } \\
\text { zona (mezclas de idiomas, tránsito } \\
\text { vecinal, etc.). }\end{array}$ \\
\hline Magnitud & $\begin{array}{l}\text { Es una línea y como tal solo tiene } \\
\text { longitud, que expresa el } \\
\text { perímetro del Estado. }\end{array}$ & $\begin{array}{l}\text { Es un área y por ello posee superficie. } \\
\text { Siempre es difícil ponderar su ancho } \\
\text { verdadero. }\end{array}$ \\
\hline $\begin{array}{l}\text { Estabilidad y } \\
\text { perdurabilidad }\end{array}$ & $\begin{array}{l}\text { Es definitivo, salvo la vigencia de } \\
\text { nuevos acuerdos de límites. }\end{array}$ & $\begin{array}{l}\text { Es inestable en su ancho y varía con la } \\
\text { situación coyuntural de los países } \\
\text { colindantes. }\end{array}$ \\
\hline $\begin{array}{l}\text { Relación con el } \\
\text { asentamiento } \\
\text { humano }\end{array}$ & $\begin{array}{l}\text { Sentido formal: su vigencia no no } \\
\text { depende del número de } \\
\text { habitantes fronterizos. }\end{array}$ & $\begin{array}{l}\text { Sentido vital: no hay frontera cabal si } \\
\text { no hay población. }\end{array}$ \\
\hline
\end{tabular}

Fuente: Rey Balmaceda, 1979

Publicado en formato digital: Aníbal Marcelo Mignone, Jorge Alfredo Alberto, Alejandra Torre Geraldi, Mabel Novoa, María Russo. CONFORMACIÓN Y ORGANIZACIÓN ACTUAL DEL ESPACIO AMERICANO A PARTIR DEL ANÁLISIS DE SUS INSTITUCIONES. Revista Geográfica Digital. IGUNNE. Facultad de Humanidades. UNNE. Año 14 . № 26. Enero - Junio 2017. ISSN 1668- 5180 Resistencia, Chaco. En: http://hum.unne.edu.ar/revistas/geoweb/default.htm 


\section{PROBLEMAS PARA ESTABLECER LÍMITES INTERNACIONALES}

- Las primeros límites se establecieron según criterio fisiográficos.

- Más fáciles de establecer pero con problemas en el transcurso de los años.

\section{Problemas del medio natural:}

- El cambio en los cursos de agua.

- Las propias dificultades de las cadenas montañosas.

- Las morrenas y su acción en el relieve.

- Los climas áridos.

- Las zonas selváticas.

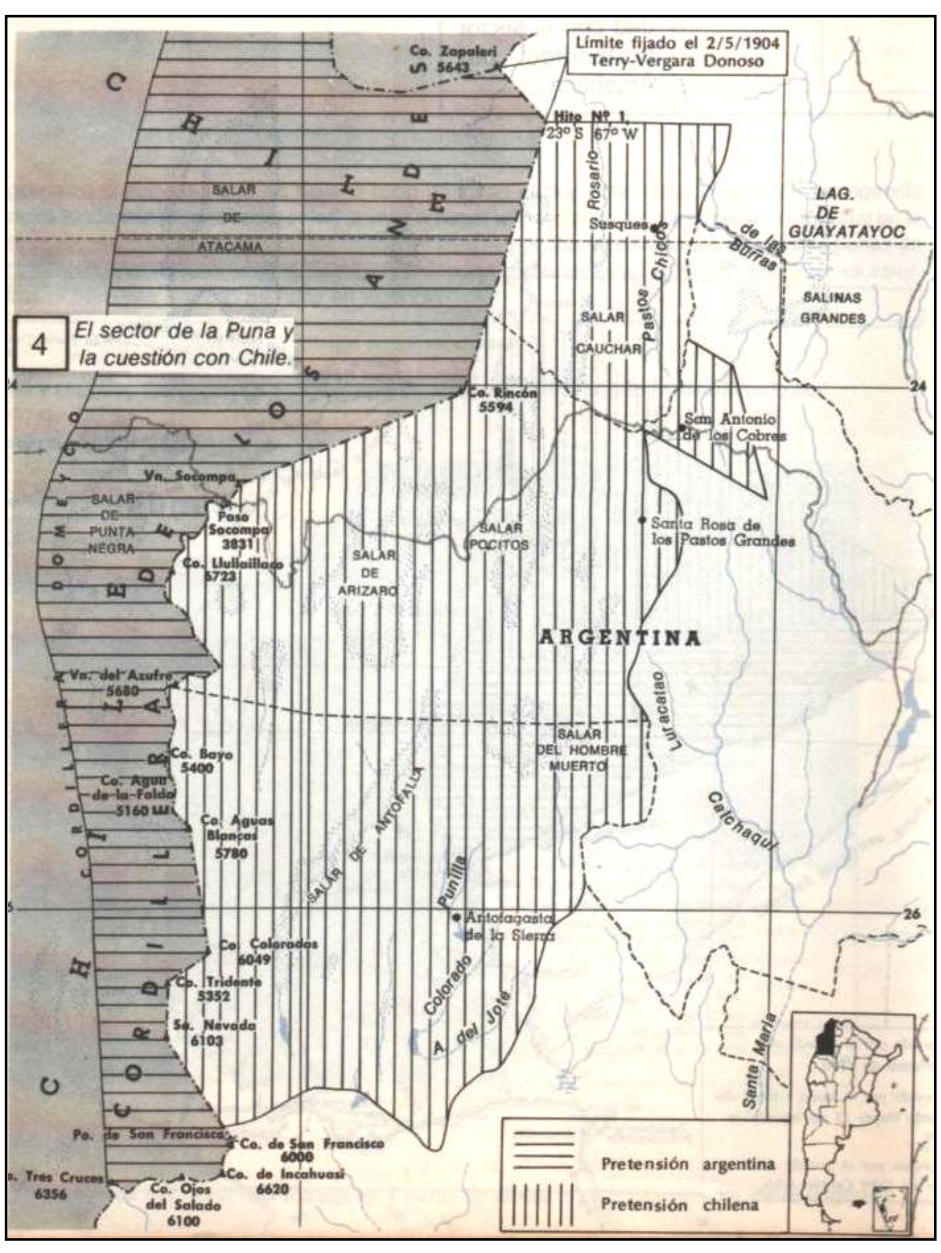

Fuente: Rey Balmaceda, 1979 


\section{CONCEPTOS DE FRONTERAS MÓVILES}

- Los espacios fronterizos son anteriores a la conformación de los Estados nacionales y a la ulterior delimitación de sus territorios políticos.

- Las fronteras pueden tener un carácter móvil; una sociedad en proceso expansivo tiende a ampliar su dominio sobre los territorios de otras sociedades con miras al control de recursos estratégicos, a través de medios militares, culturales, políticos, comerciales, etc.

- Se afianza la apreciación de las fronteras, no como un "simple" límite físico, sino como una construcción social (Vargas, 1993)

- La ocupación de las fronteras es, entonces, el proceso a través del cual una sociedad en expansión toma territorios de otras sociedades absorbiéndolas, destruyéndolas 0 desplazándolas.

- Un rasgo que comparten varias de las fronteras móviles es la articulación entre origen y $\underline{\text { destino }}$ mediante fuertes lazos históricos y culturales entre pueblos de disímiles orígenes (Canales, Vargas y Montiel, 2010) 


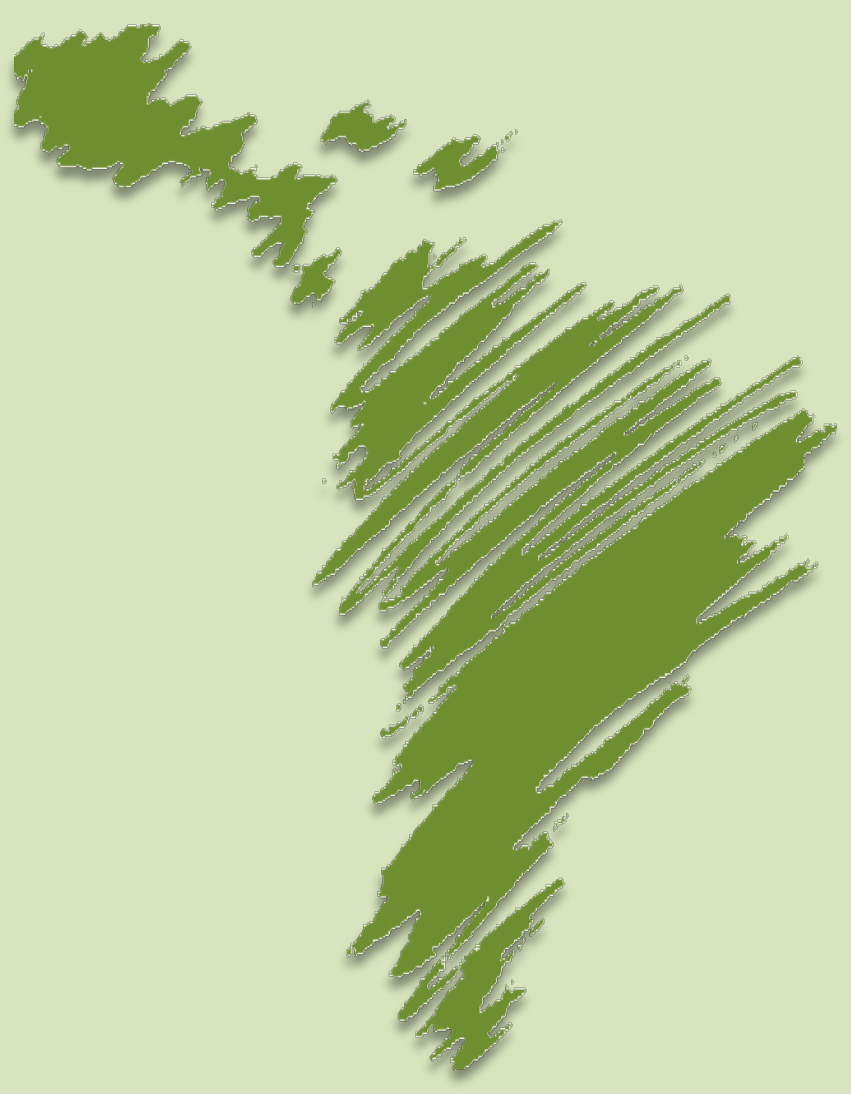

\section{HECHOS Y PROCESOS HISTÓRICOS SIGNIFICATIVOS EN AMÉRICA}




\section{Guerra de Secesión de Estados Unidos}

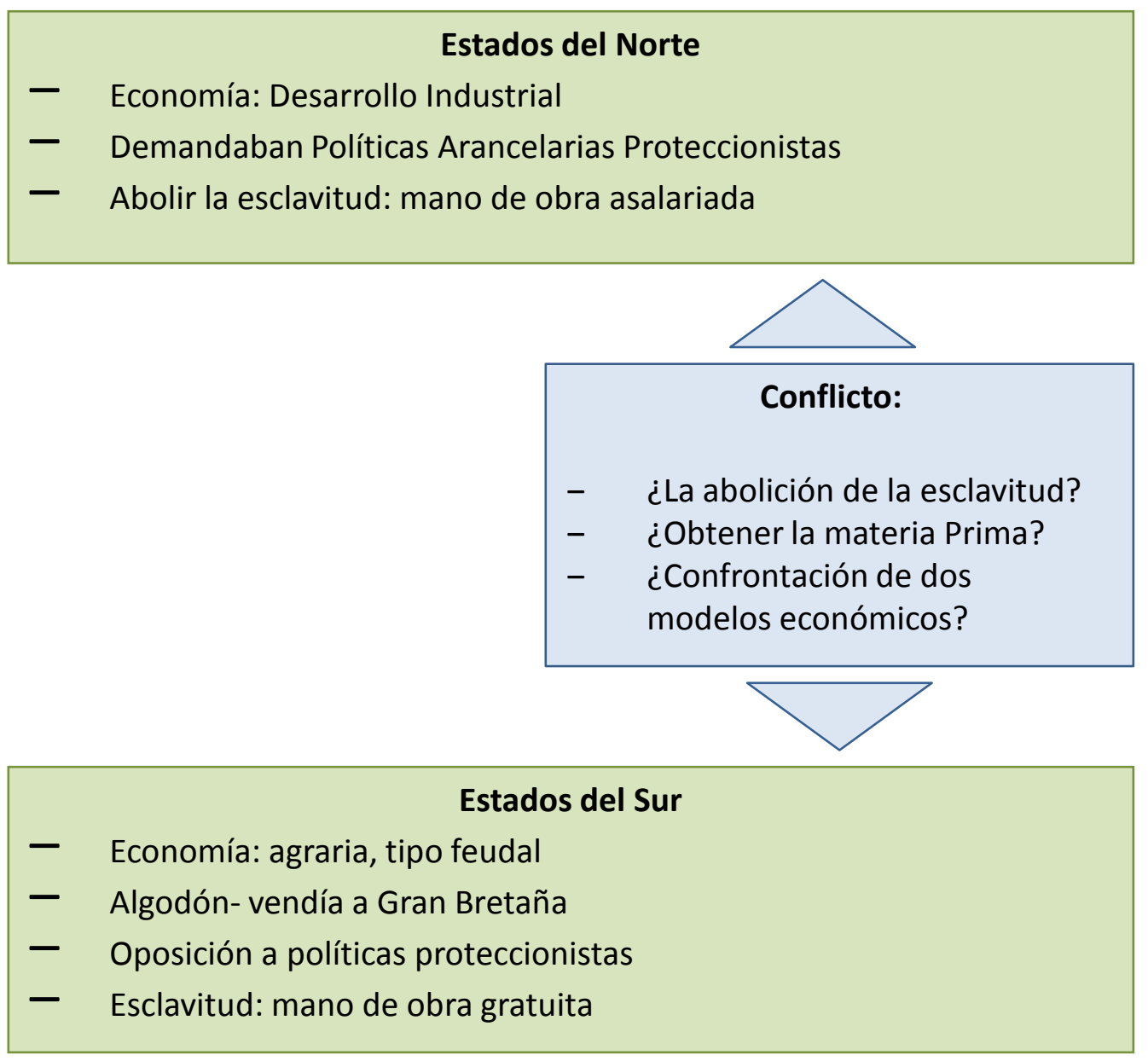

Resultados
Estados Unidos se consolida
como potencia económica por
su desarrollo industrial.
Problema racial no resuelto
hasta la actualidad.
Ocupación y reorganización del
territorio.
Acentuación de procesos
migratorios.
Modelos y políticas de
distribución de la tierra.
( ley de tierras o Land
Ordinance de 1785 )

Publicado en formato digital: Aníbal Marcelo Mignone, Jorge Alfredo Alberto, Alejandra Torre Geraldi, Mabel Novoa, María Russo. CONFORMACIÓN Y ORGANIZACIÓN ACTUAL DEL ESPACIO AMERICANO A PARTIR DEL ANÁLISIS DE SUS INSTITUCIONES. Revista Geográfica Digital. IGUNNE. Facultad de Humanidades. UNNE. Año 14. № 26. Enero - Junio 2017. ISSN 1668- 5180 Resistencia, Chaco. En: http://hum.unne.edu.ar/revistas/geoweb/default.htm 


\section{Sistema de ocupación de tierras en Estados Unidos (tomado de Melina Yuln)}

Durante el periodo colonial se desarrollaron dos sistemas de tierras muy definidos, el de Nueva Inglaterra y el del sur. "Township planting" fue la base del sistema de Nueva Inglaterra y fue perfeccionado durante el siglo XVIII. El trazado del township o municipio antecedía a la propiedad privada y no se podía tener título de propiedad por fuera de sus límites. Dentro del township (municipio cuya área equivalía a seis millas cuadradas) la tierra fue dividida en fracciones -por la colonia, por el pueblo o por los propietarios- y esas fracciones fueron identificadas por calidad. Los planos fueron cuidadosamente trazados y los límites registrados, de modo que las mensuras casi siempre precedían al poblamiento. Aquí apareció la tradición de la venta de tierras en subasta pública. Durante el siglo XVIII fueron trazados varios grupos dentro de este sistema. El éxito del sistema de township planting impresionó de tal manera al gobierno local que las instrucciones del gobierno de Carolina del Sur, en 1730, contenían la demarcación de once townships en las sesenta millas cuadradas de Charleston, en planos cuadrados de 20.000 acres cada uno.

Treat, Payson Jackson, The National Land System 1785-1820, E.B. Treat \& Co., 1910, New York.

En el sur, la tierra era ocupada por medio de la presentación de poderes o garantías, en cualquier zona sin propietarios. Las mensuras debían ser realizadas por agrimensores públicos, pero como la mayoría fueron hechas por funcionarios de poca experiencia, la posibilidad de error siempre estuvo presente. El sistema de Virginia (1779) pedía garantías, certificados y subvenciones a cambio de la tierra -era un sistema complicado en comparación con la escritura simple de Nueva Inglaterra- y los registros fueron mal conservados

Ambos sistemas fueron la encarnación de la experiencia colonial norteamericana. El de Nueva Inglaterra se adaptó a una población libre, con una tradición de vida comunitaria, si bien forzada, por la necesidad de protección contra los indios y la ayuda mutua durante los inviernos crudos en esas latitudes. El del Sur fue parte del proceso de una sociedad de grandes plantaciones y trabajo esclavo, indios menos hostiles y un clima más favorable, que permitió la extensión y la dispersión de los asentamientos en las tierras costeras mientras en el interior del país el sistema permitía a los pioneros localizarse en las mejores tierras a lo largo de los arroyos.

Lectura recomendada Melina Yuln. "El territorio cuadriculado. La adaptación de un modelo territorial estadounidense en Argentina, 1850-1890".

[En línea [06/12/2012] https://nuevomundo.revues.org/64653]

Publicado en formato digital: Aníbal Marcelo Mignone, Jorge Alfredo Alberto, Alejandra Torre Geraldi, Mabel Novoa, María Russo. CONFORMACIÓN Y ORGANIZACIÓN ACTUAL DEL ESPACIO AMERICANO A PARTIR DEL ANÁLISIS DE SUS INSTITUCIONES. Revista Geográfica Digital. IGUNNE. Facultad de Humanidades. UNNE. Año 14. № 26. Enero - Junio 2017. ISSN 1668- 5180 Resistencia, Chaco. En: http://hum.unne.edu.ar/revistas/geoweb/default.htm 


\section{Guerra del "Pacífico", del "Guano" o del "Salitre"}

\section{Conflicto bélico entre Chile y Perú-Bolivia (1879-1883)}
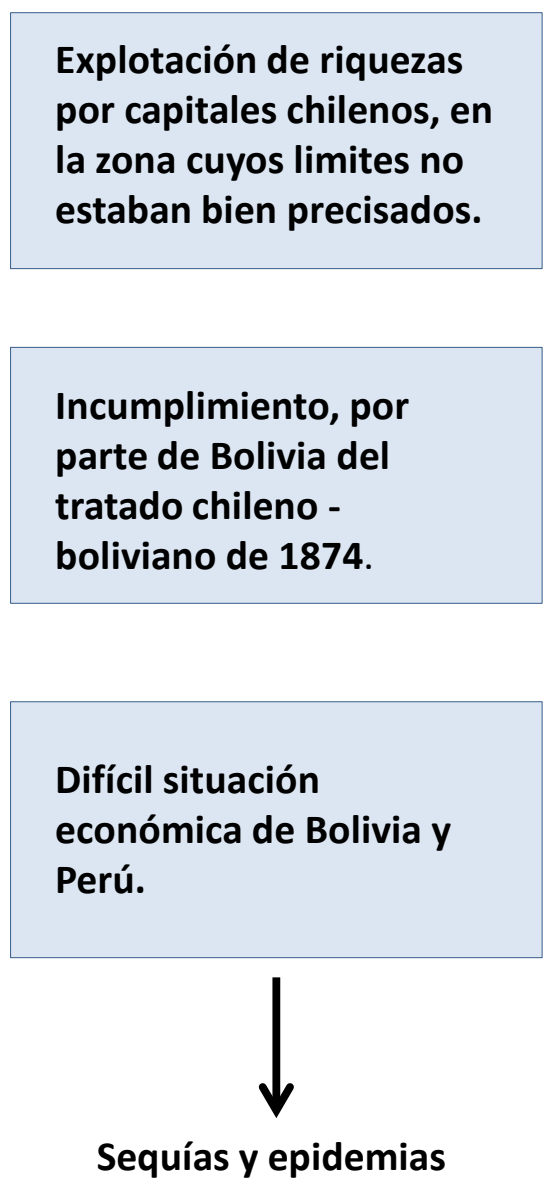

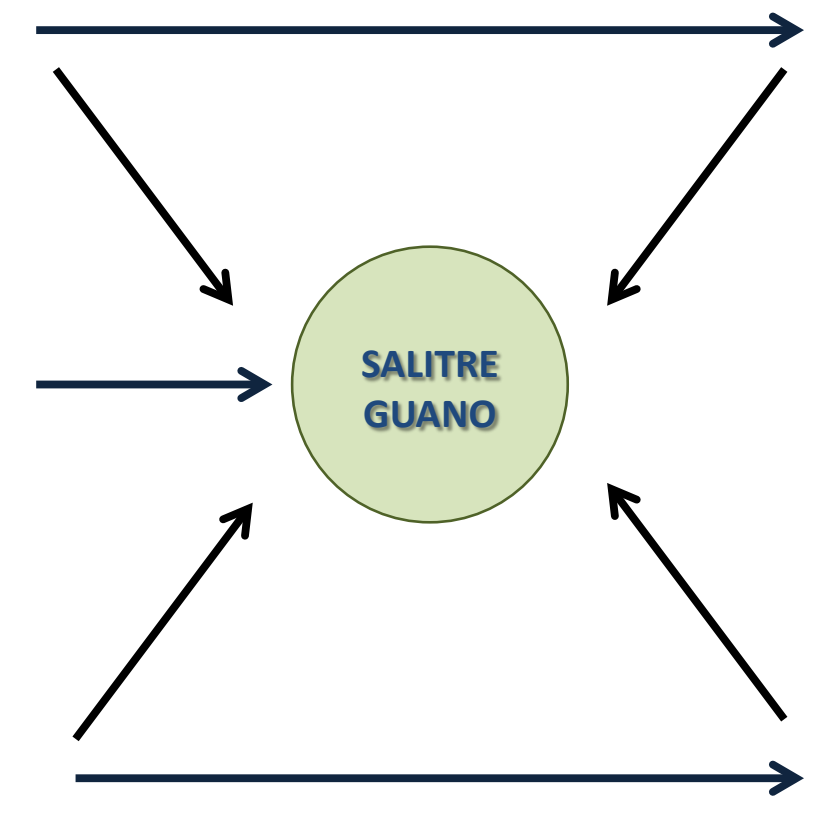

\section{Defectuosa} demarcación de los límites entre Chile y Bolivia.
Aspiraciones hegemonías de Perú en la región del Pacifico sur. 


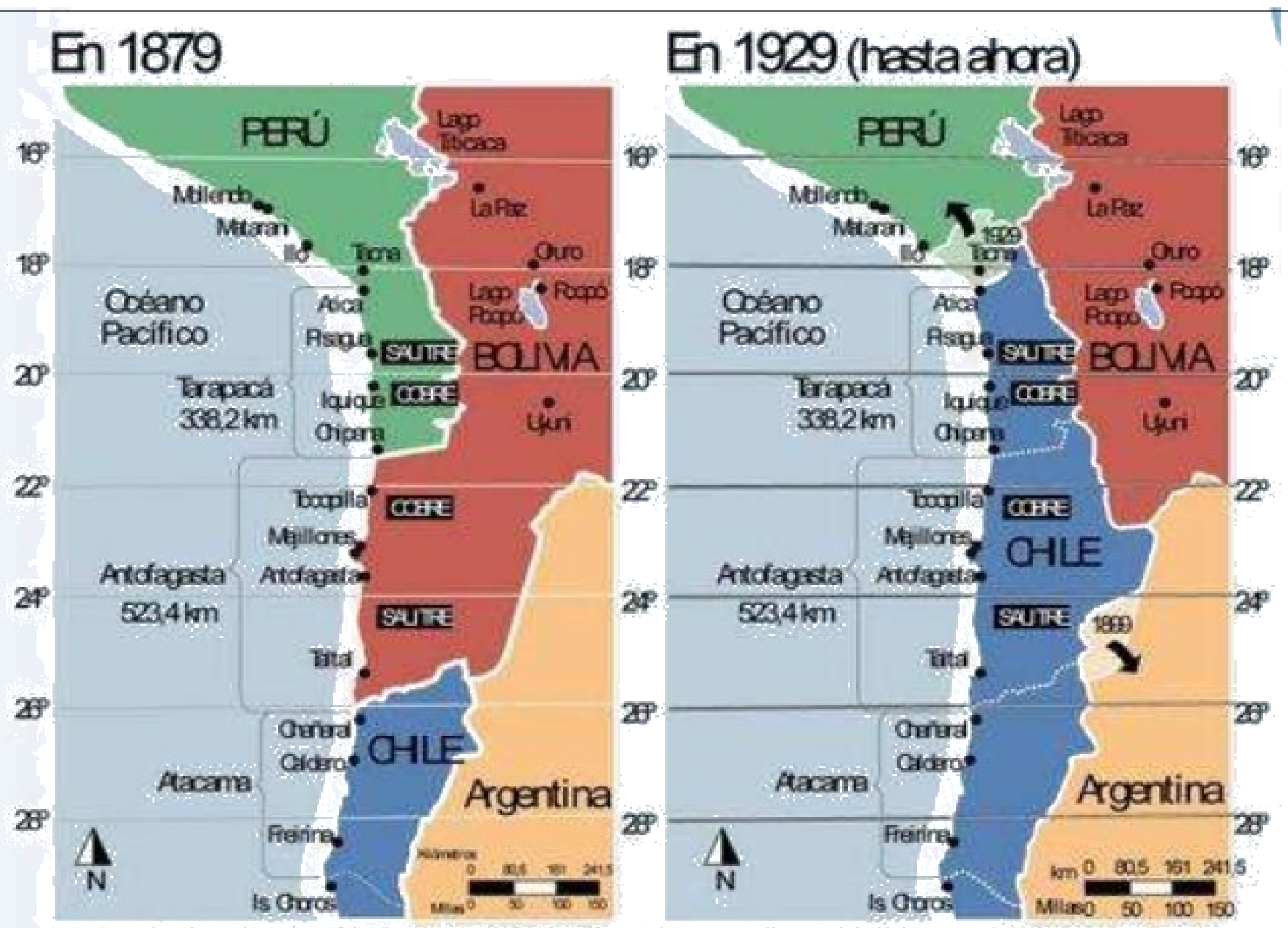

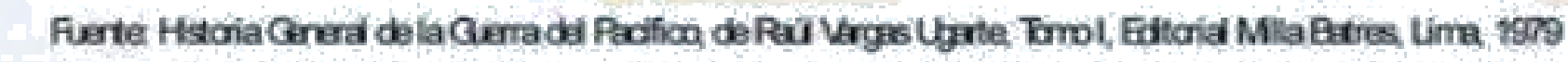

Fuente: Imagen óbténida de Katty Nicole, 2014

Publicado en formato digital: Aníbal Marcelo Mignone, Jorge Alfredo Alberto, Alejandra Torre Geraldi, Mabel Novoa, María Russo. CONFORMACIÓN Y ORGANIZACIÓN ACTUAL DEL ESPACIO AMERICANO A PARTIR DEL ANÁLISIS DE SUS INSTITUCIONES. Revista Geográfica Digital. IGUNNE. Facultad de Humanidades. UNNE. Año 14. № 26. Enero - Junio 2017. ISSN 1668- 5180 Resistencia, Chaco. En: http://hum.unne.edu.ar/revistas/geoweb/default.htm 


\section{Guerra del "Pacífico", del "Guano" o del "Salitre"}

\section{Conflicto bélico entre Chile y Perú-Bolivia (1879- 1883)}

\section{Victoria para Chile: acrecentó sus territorios y obtuvo salitre, guano y cobre.}

Se acentúan las inversiones extranjeras en lo referido a la extracción de minerales y desarrollo de infraestructuras para la misma.

Derrota militar y perdida de territorios con importantes recursos minerales por parte de Perú y Bolivia.

Perdida de una salida al mar de Bolivia que se convierte en un país mediterráneo.

Se profundizan las crisis políticas e estacionales al igual que las socioeconómicas en estos países.
A largo del siglo XX, Bolivia ha reclamado una salida soberana al mar.

Ha sido un importante impedimento para su desarrollo económico y social.

En 2015 el proceso ha sido llevado al tribunal de la Haya, dando el fallo a favor de Bolivia y la declara competente para negociar una salida al Océano Pacífico. 


\section{Guerra del Chaco}

Conflicto bélico entre Bolivia y Paraguay (1932 - 1935)

\begin{tabular}{|l|l|}
\hline \multicolumn{1}{|c|}{ BOLIVIA } & \multicolumn{1}{|c|}{ PARAGUAY } \\
\hline $\begin{array}{l}\text { Alegó derechos sobre todo el } \\
\text { territorio hasta los ríos Paraguay y } \\
\begin{array}{l}\text { Pilcomayo, con títulos emanados de } \\
\text { la Audiencia de Charcas }\end{array}\end{array}$ & $\begin{array}{l}\text { Derechos provenientes de las } \\
\text { ordenaciones de la Corona } \\
\text { española, desde las Capitulaciones } \\
\text { del siglo XVI hasta las Ordenanzas } \\
\text { de Intendentes de 1782 }\end{array}$ \\
\hline \multicolumn{2}{|c|}{ Cuatro tratados de límites (entre 1879 y 1907) } \\
no aceptados por ninguna de las dos partes
\end{tabular}

Fuente: Cardozo, 2007. Imagen obtenida de Llacer Riaño, 15/06/2014

Publicado en formato digital: Aníbal Marcelo Mignone, Jorge Alfredo Alberto, Alejandra Torre Geraldi, Mabel Novoa, María Russo. CONFORMACIÓN Y ORGANIZACIÓN ACTUAL DEL ESPACIO AMERICANO A PARTIR DEL ANÁLISIS DE SUS INSTITUCIONES. Revista Geográfica Digital. IGUNNE. Facultad de Humanidades. UNNE. Año 14. № 26 . Enero - Junio 2017. ISSN 1668- 5180 Resistencia, Chaco. En: http://hum.unne.edu.ar/revistas/geoweb/default.htm 


\section{Guerra del Chaco}

\section{Conflicto bélico entre Bolivia y Paraguay (1932 - 1935)}
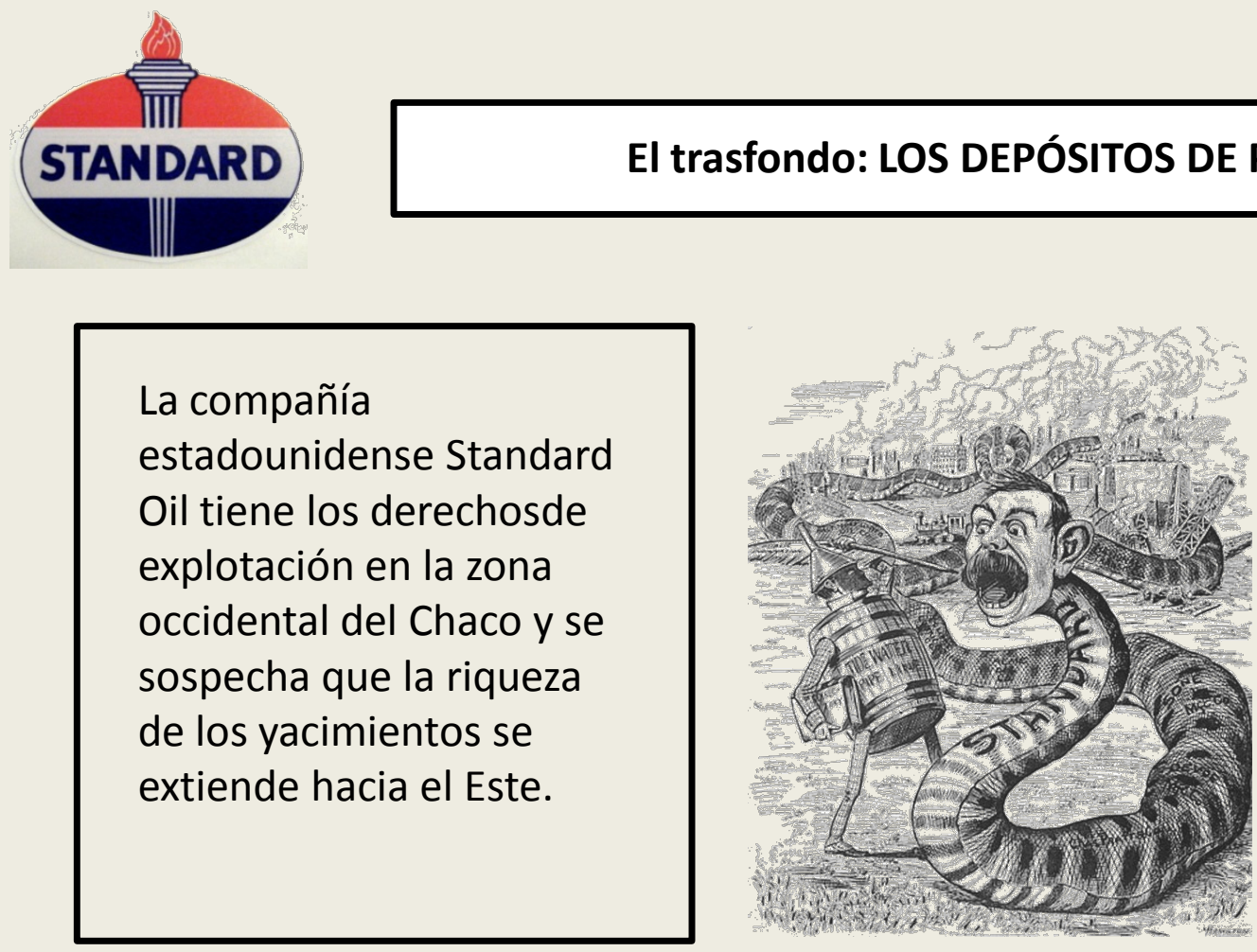

El problema es que el

Chaco Boreal es controlado por los paraguayos y los derechos de exploración pertenecen a la compañía angloholandesa Royal Dutch Shell.

Fuente: Historia y Biografías, S/f. Imágenes obtenida de Significance of The History Of The Estandar Oil Company. S/f.

Publicado en formato digital: Aníbal Marcelo Mignone, Jorge Alfredo Alberto, Alejandra Torre Geraldi, Mabel Novoa, María Russo. CONFORMACIÓN Y ORGANIZACIÓN ACTUAL DEL ESPACIO AMERICANO A PARTIR DEL ANÁLISIS DE SUS INSTITUCIONES. Revista Geográfica Digital. IGUNNE. Facultad de Humanidades. UNNE. Año 14 . № 26 . Enero - Junio 2017. ISSN 1668- 5180 Resistencia, Chaco. En: http://hum.unne.edu.ar/revistas/geoweb/default.htm 


\section{National Fruit Company (La Frutera o El Pulpo)}

Conocida como la frutera, el Pulpo o la Yunai (en Costa Rica), era una firma comercial multinacional estadounidense.

\section{Producía y comercializaba frutas}

tropicales (principalmente banano)

cultivados en América Latina.

Con filiales en la mayoría de los países de América Central y Colombia.

\section{Se convirtió en una fuerza política y económica determinante durante el siglo XX.}

Influyo decisivamente sobre gobiernos y partidos para mantener sus operaciones con el mayor margen posible de ganancias, al extremo de auspiciar golpes de estado y sobornar políticos.

Esta empresa es conocida por una disputa en el territorio de Colombia llamada la Masacre de las Bananeras en el año 1928.

Lectura recomendada: [En línea [06/12/2012]

https://es.wikipedia.org/wiki/Masacre_de_las_Bananeras
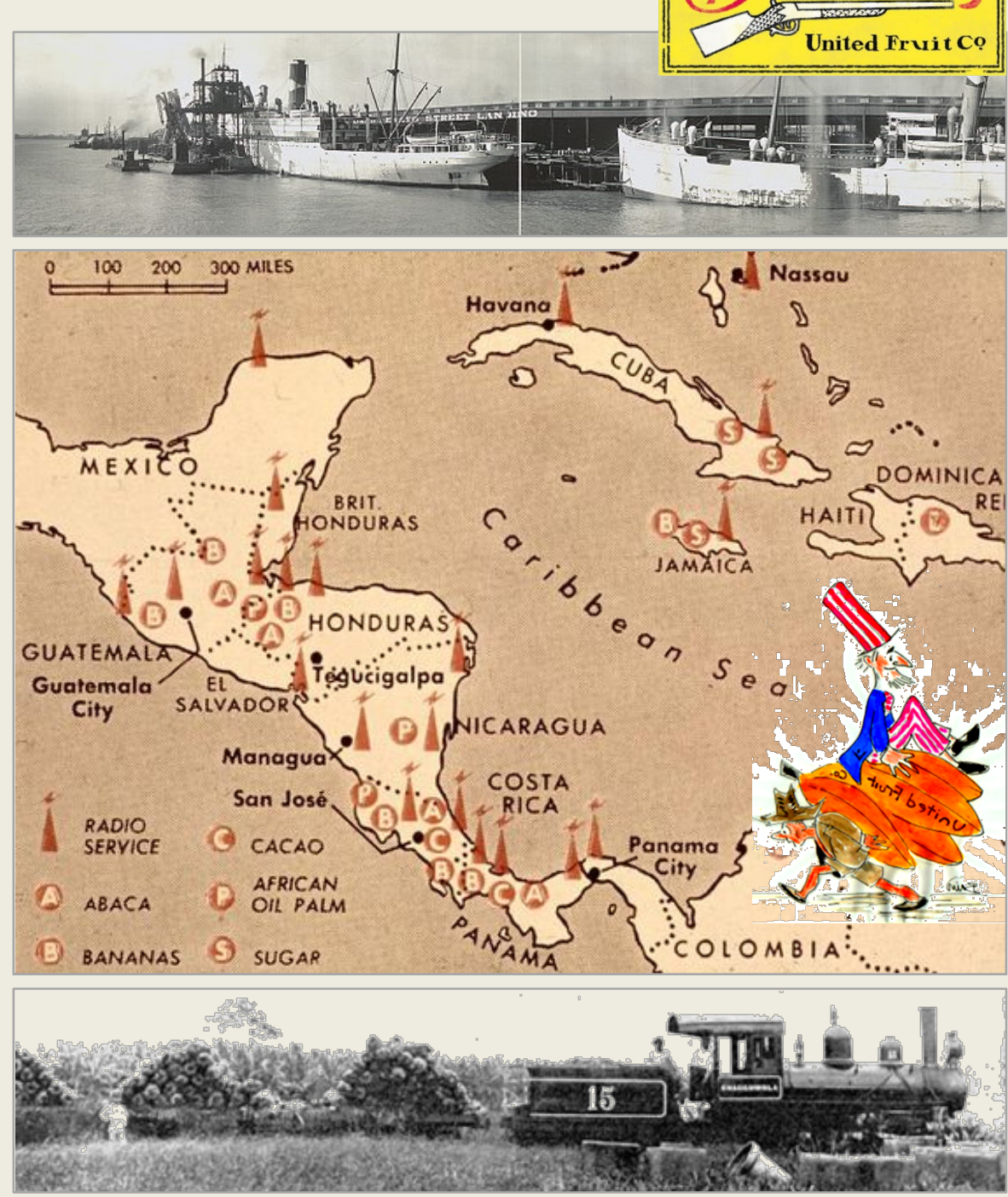


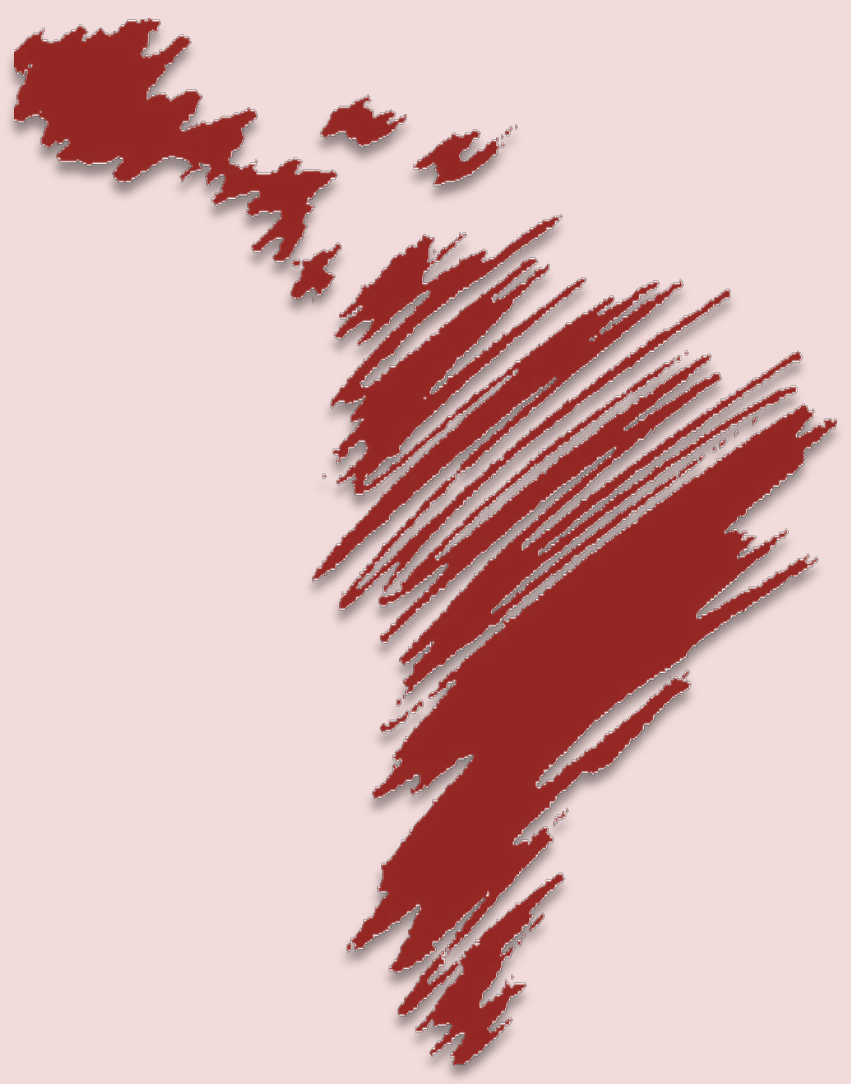

\section{ESTUDIO DE CASOS}




\section{Estudio de caso ${ }^{\circ}$ 1: La frontera entre México y Estados Unidos}

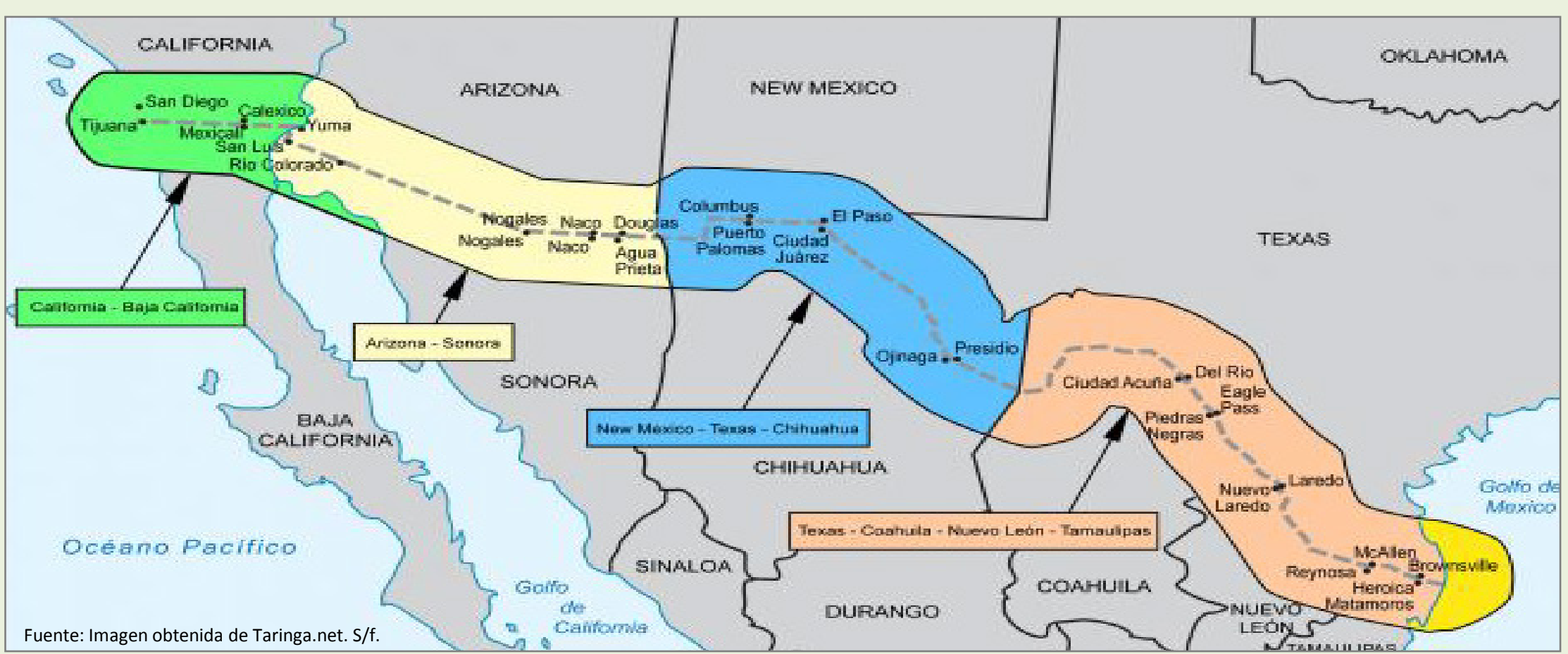

La frontera entre Estados Unidos de América y México es el límite geográfico-político entre naciones que parte del Océano Pacífico y culmina en el Océano Atlántico tiene una longitud de 3185 kilómetros.

Atraviesa grandes áreas urbanas y desiertos inhóspitos, se encuentra a lo largo del Río Bravo (conocido en EE.UU. como Río Grande), para luego cruzar los desiertos Sonora y Chihuahua, atravesar un tramo del río Colorado, llegar al norte de la Baja California y finalizar su recorrido en el océano Pacífico.

Lectura recomendada: [En línea [06/12/2016] https://es.wikipedia.org/wiki/Frontera_entre_Estados_Unidos_y_Mexico 
La historia de la frontera mexicana señala que uno de los primeros factores ha sido la vocación como área turística y creadora de empleo en esa clase de servicios.

Más cercano en el tiempo es la nueva industrialización de la zona a través de plantas de las "maquilas", que ocupan el 20 por ciento de la población económicamente activa (PEA) industrial del total del país.

Una maquiladora es una empresa que importa materiales sin pagar aranceles; su producto se comercializa en el país de origen de la materia prima. El término se originó en México, país donde el fenómeno de las maquiladoras está ampliamente extendido. En marzo del 2006 el personal ocupado por las maquilas mexicanas era de 1.300 .000 personas.

Lectura recomendada: [En línea [06/12/2016] https://es.wikipedia.org/wiki/Maquiladora

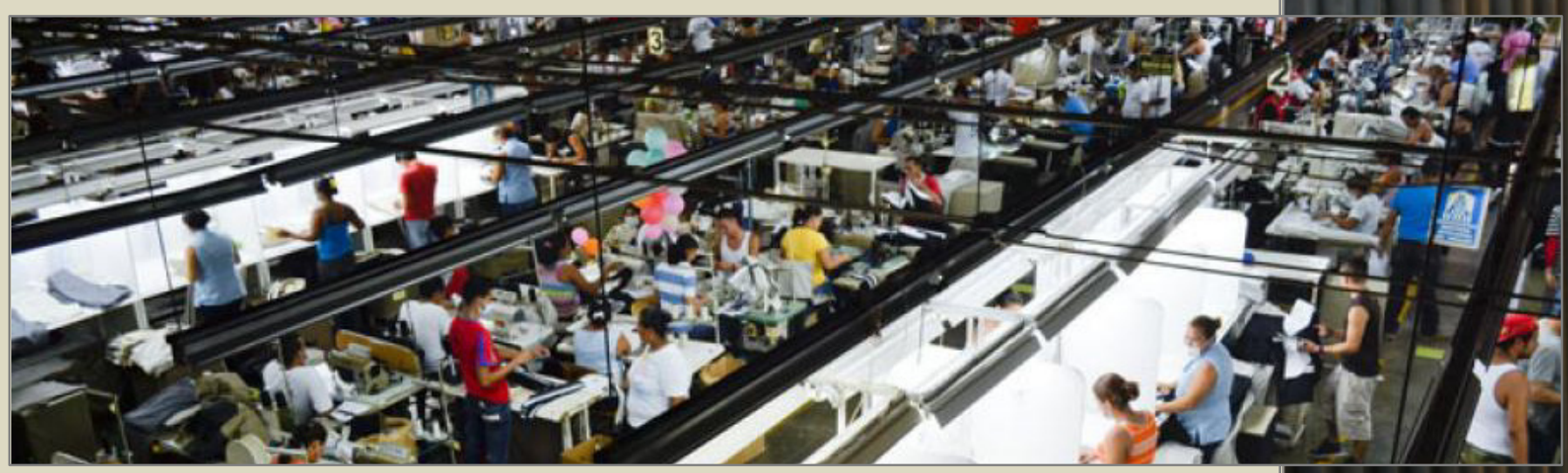

La capacidad de crecimiento demográfico se ha sostenido a partir de:

- Desarrollo comercial

- Los servicios al turismo

- Convenios bilaterales de migración

- Localización de la industria manufacturera de exportación
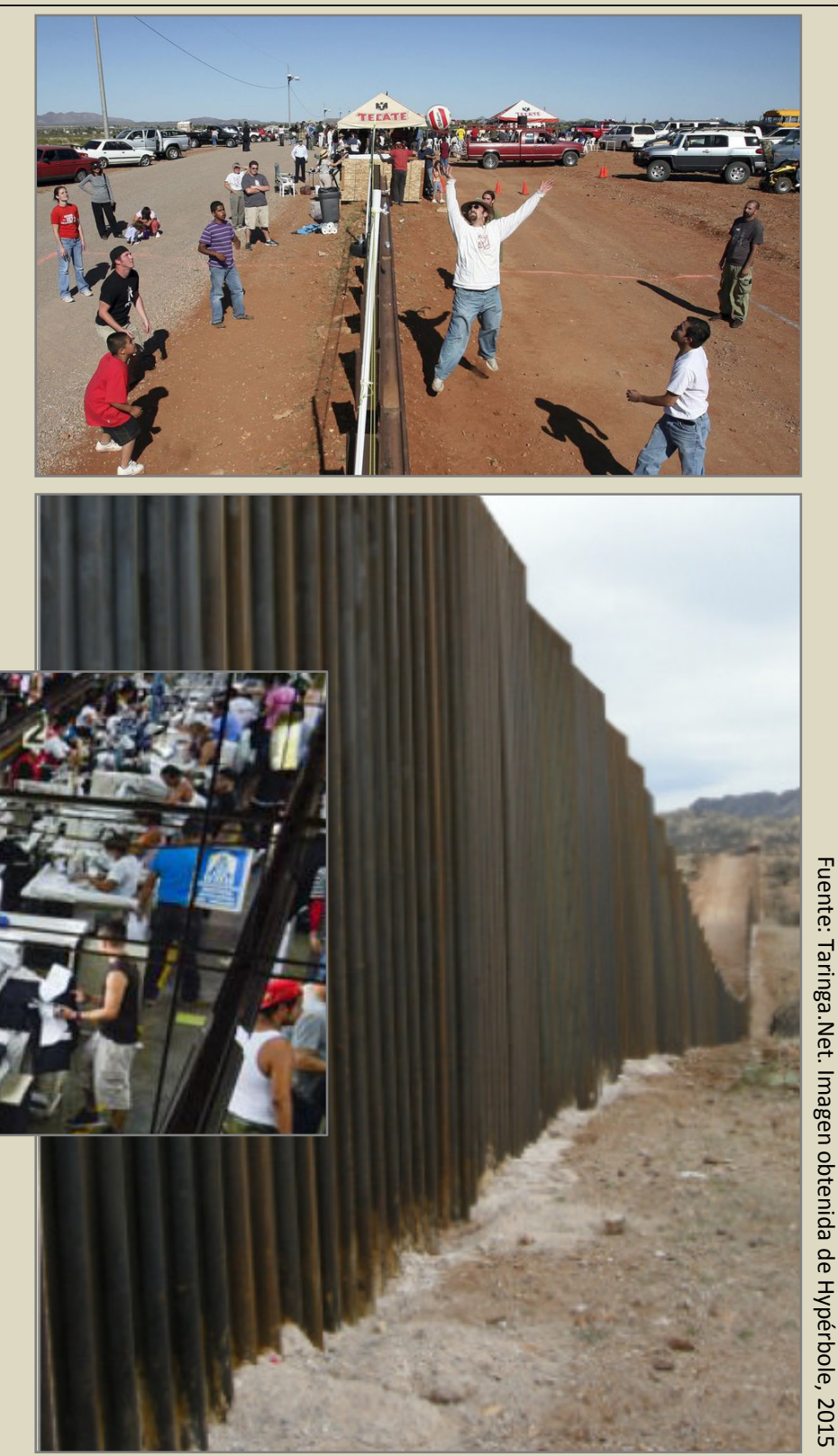

Publicado en formato digital: Aníbal Marcelo Mignone, Jorge Alfredo Alberto, Alejandra Torre Geraldi, Mabel Novoa, María Russo. CONFORMACIÓN Y ORGANIZACIÓN ACTUAL DEL ESPACIO AMERICANO A PARTIR DEL ANÁLISIS DE SUS INSTITUCIONES. Revista Geográfica Digital. IGUNNE. Facultad de Humanidades. UNNE. Año 14. № 26. Enero - Junio 2017. ISSN 1668- 5180 Resistencia, Chaco. En: http://hum.unne.edu.ar/revistas/geoweb/default.htm 


\section{Factores de la migración de mexicanos a Estados Unidos}

Es posible agrupar los factores que estructuran el complejo sistema migratorio en tres grandes categorías (Conapo, 1999):

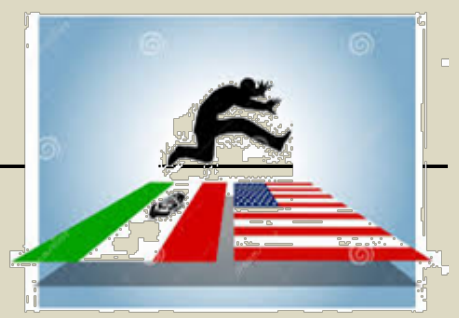

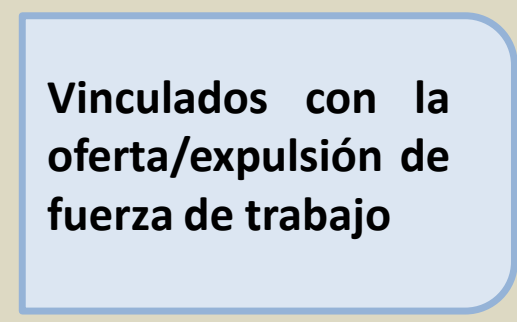

Asociados con la demanda/atracción

Factores sociales

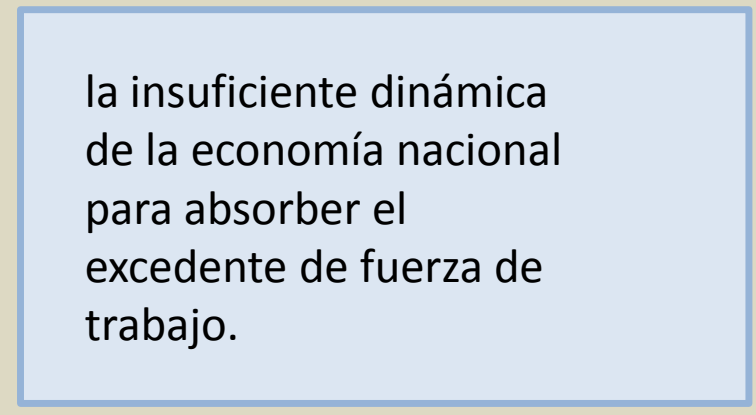

la evolución de los sectores agrícola, industrial y de servicios de Estados Unidos y la demanda de fuerza de trabajo migrante que ocupan.

que ligan a las comunidades de origen y de destino, y que son determinantes para reducir los costos y riesgos asociados con el movimiento migratorio a Estados Unidos.
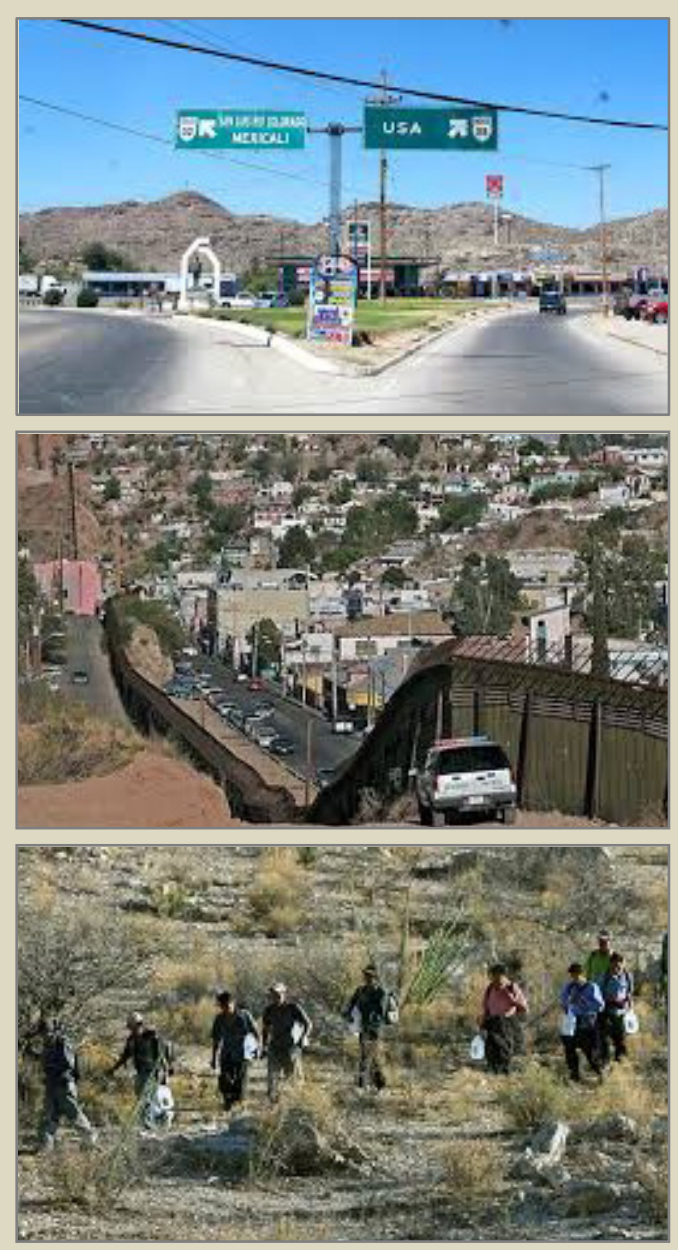

Publicado en formato digital: Aníbal Marcelo Mignone, Jorge Alfredo Alberto, Alejandra Torre Geraldi, Mabel Novoa, María Russo. CONFORMACIÓN Y ORGANIZACIÓN ACTUAL DEL ESPACIO AMERICANO A PARTIR DEL ANÁLISIS DE SUS INSTITUCIONES. Revista Geográfica Digital. IGUNNE. Facultad de Humanidades. UNNE. Año 14. № 26. Enero - Junio 2017. ISSN 1668- 5180 Resistencia, Chaco. En: http://hum.unne.edu.ar/revistas/geoweb/default.htm 


\section{La demanda laboral}

La mano de obra migrante es importante y una elevada fracción se desempeña en actividades agrícolas.

Esas actividades tienen lugar en zonas rurales poco pobladas, su presencia no es "visible socialmente".

Otra parte importante de los migrantes trabaja en actividades de servicios y manufactureras que no exigen mayor calificación.

Aunque los empleos deparan ingresos inferiores a los salarios medios de los Estados Unidos, sus montos exceden a los que podría obtenerse en ocupaciones similares en el país de origen.

Son "visibles socialmente" en las ocupaciones manufactureras y de servicios, particularmente en los aglomerados metropolitanos.

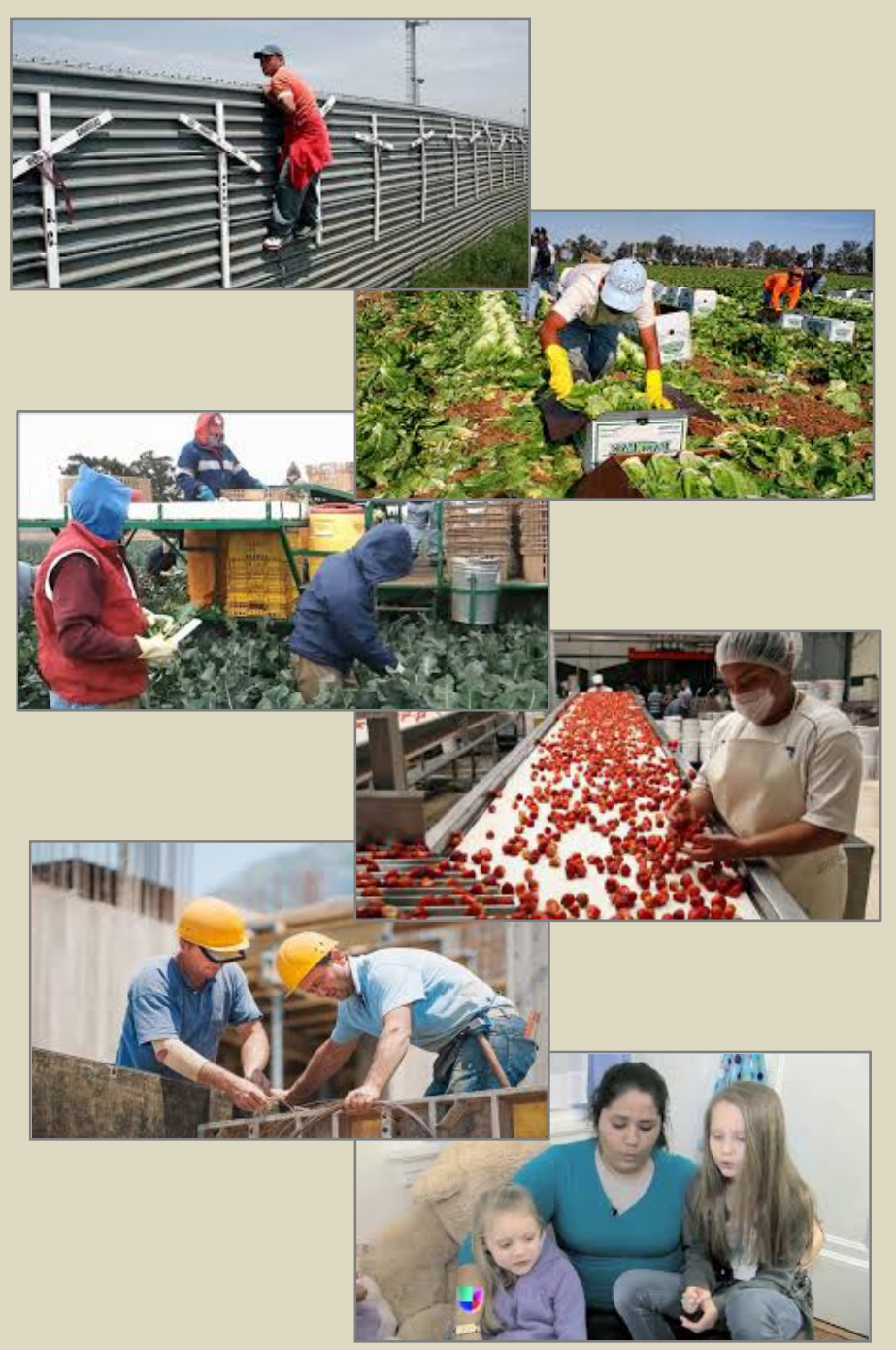




\section{Maquilas y trabajo femenino}

La situación de la mujer como persona independiente genera un desplazamiento de la figura del hombre autoritario, propio del sistema patriarcal.

La introducción de la mujer en el ámbito laboral productivo alimenta el sentimiento de menosprecio del "macho" hacia el sexo opuesto y genera una sensación de inferioridad al hombre (Sánchez Martín, 2007).

El hombre actúa y responde con la fuerza.

El género ha sido usado para disminuir condiciones laborales $y$ producir sujetos controlables en el espacio de trabajo y condenados a permanecer en una misma posición laboral durante toda su vida productiva.

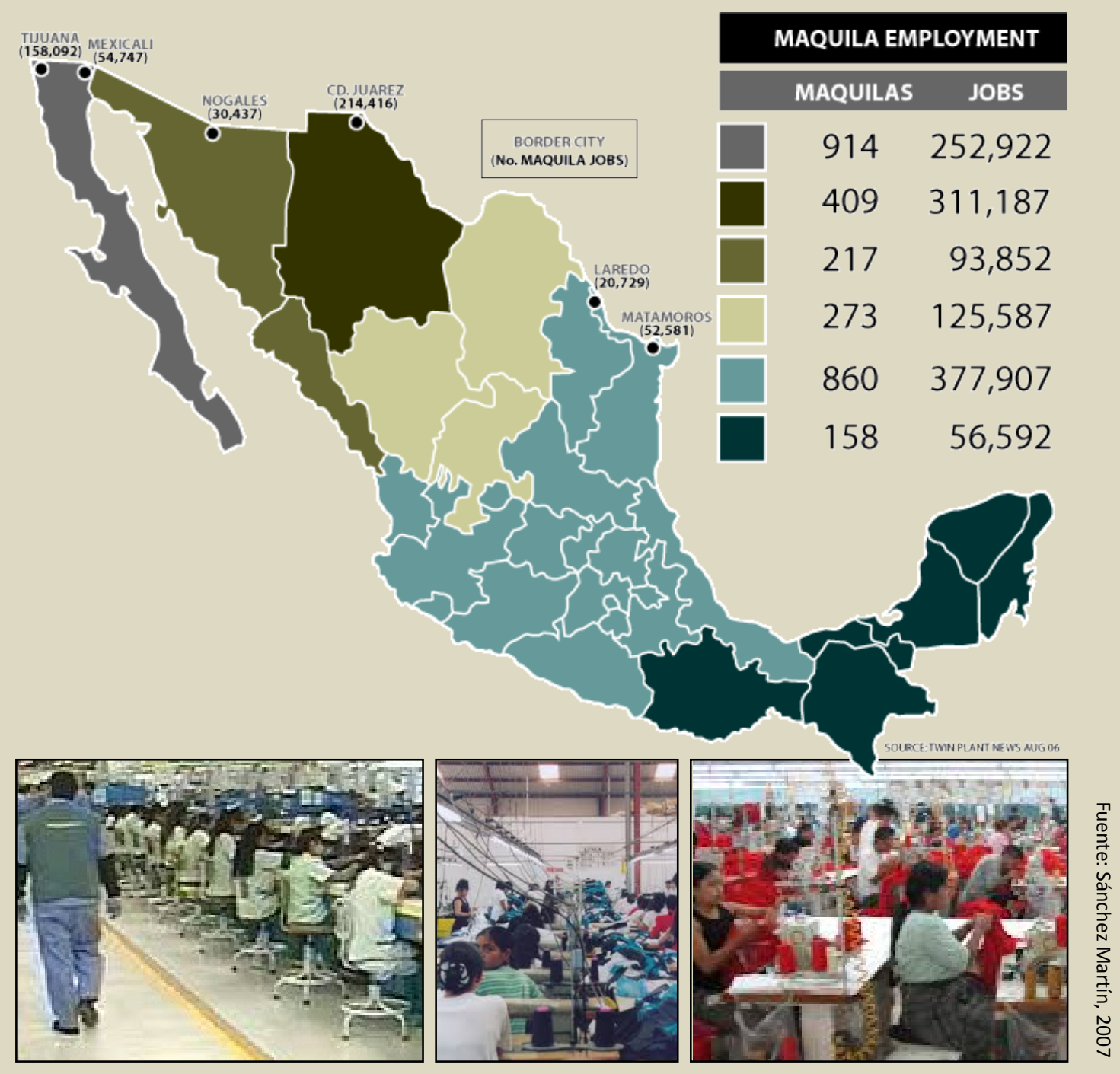

Publicado en formato digital: Aníbal Marcelo Mignone, Jorge Alfredo Alberto, Alejandra Torre Geraldi, Mabel Novoa, María Russo. CONFORMACIÓN Y ORGANIZACIÓN ACTUAL DEL ESPACIO AMERICANO A PARTIR DEL ANÁLISIS DE SUS INSTITUCIONES. Revista Geográfica Digital. IGUNNE. Facultad de Humanidades. UNNE. Año 14. № 26 . Enero - Junio 2017. ISSN 1668- 5180 Resistencia, Chaco. En: http://hum.unne.edu.ar/revistas/geoweb/default.htm 


\section{Estudio de caso $n^{\circ}$ 2: La frontera entre Colombia y Venezuela o "Colombo-Venezolana"}

Son 2219 km. de límite internacional. Se establece definitivamente en 1941 (Tratado López de Mesa - Gil Borges)

\section{Problemas:}

\section{Aspecto Físico}

El límite sigue tramos con accidentes geográficos (cambio de los cursos de agua) y líneas geodésicas.

\section{Aspecto Económico}

El contrabando (bachaquear) por diferencias en el valor de las monedas.

\section{Aspecto Social}

Pueblos de la Guajira que se desplazan entre ambos países. Indocumentados.

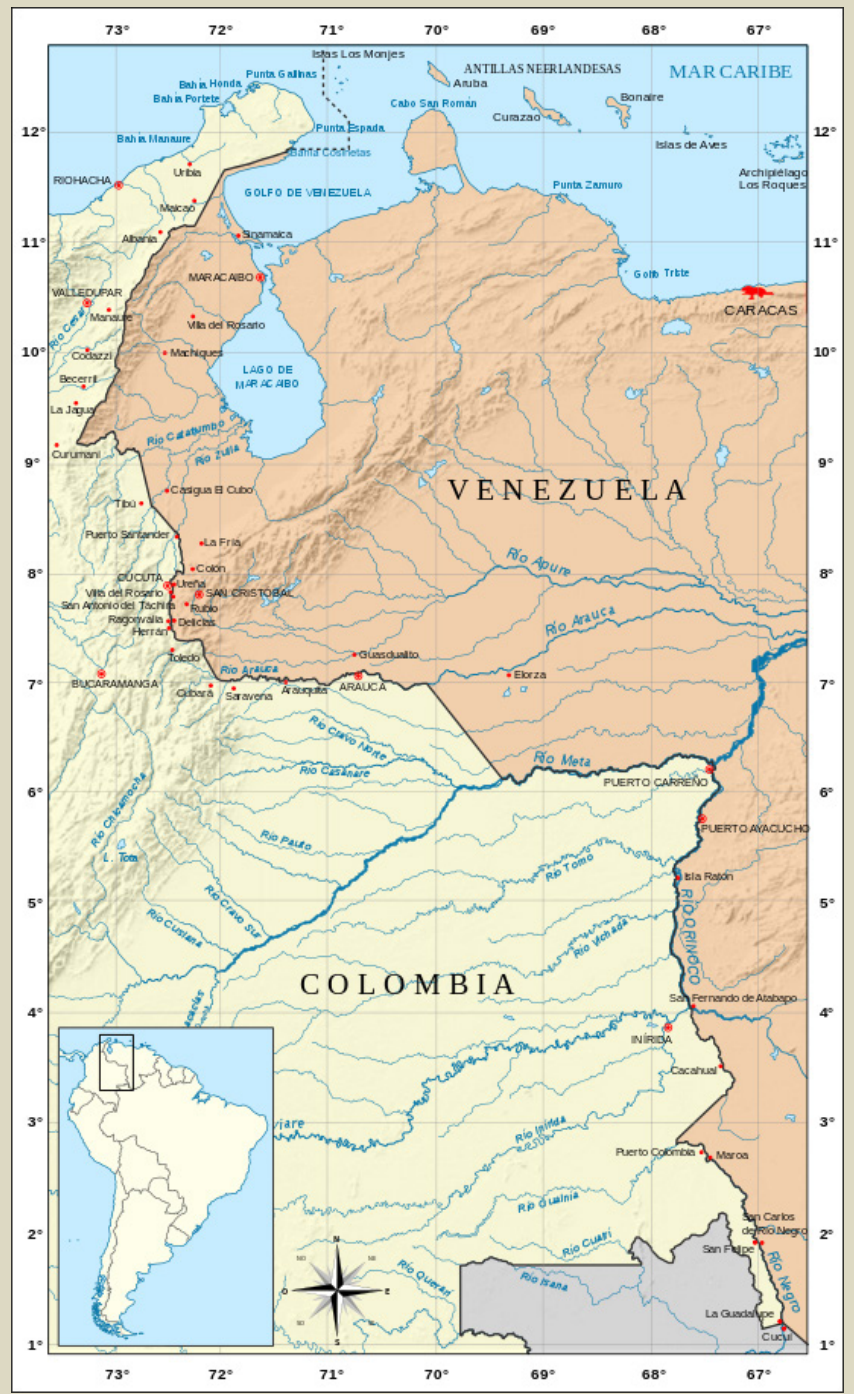




\section{La frontera entre Colombia y Venezuela o "Colombo-Venezolana"}

Actos de violencia:

Narcotráfico

Guerrilla

Bandolerismo

Ámbito militarizado.

Escasa acción Estatal.

Afecta:

- Pueblos originarios como Wayuu y Añuu.

- Se impide pesca del cangrejo y camarón.

Da lugar al:

- Contrabando de gasolina

- Alimentos

- Medicina

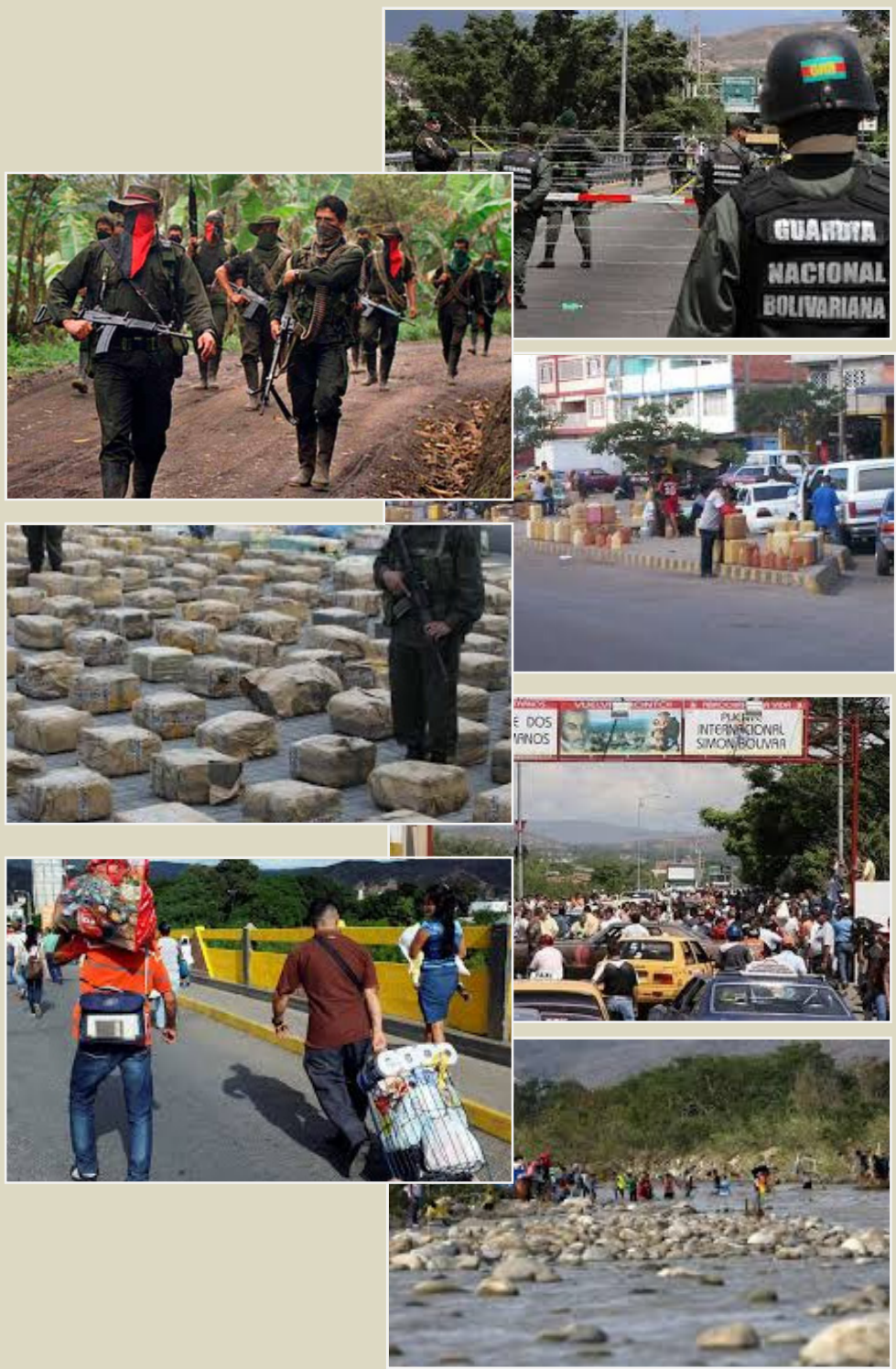

Publicado en formato digital: Aníbal Marcelo Mignone, Jorge Alfredo Alberto, Alejandra Torre Geraldi, Mabel Novoa, María Russo. CONFORMACIÓN Y ORGANIZACIÓN ACTUAL DEL ESPACIO AMERICANO A PARTIR DEL ANÁLISIS DE SUS INSTITUCIONES. Revista Geográfica Digital. IGUNNE. Facultad de Humanidades. UNNE. Año 14. № 26. Enero - Junio 2017. ISSN 1668- 5180 Resistencia, Chaco. En: http://hum.unne.edu.ar/revistas/geoweb/default.htm 


\section{Estudio de caso $n^{\circ}$ 3: La frontera entre Colombia y Ecuador o "Colombo-Ecuatoriana"}

La frontera entre el Ecuador y Colombia es un modelo de región transfronteriza que presenta una dinámica migratoria diferente.

- Las personas involucradas, el patrón de movilidad y las causas de la migración, son diferentes a los que se observa en el resto de ambos países.

- Las amenazas a la integridad de algunas poblaciones colombianas están fuertemente asociadas a una migración sin opciones $y$ claramente forzada.

- La situación de violencia e inestabilidad social y política que afecta a las regiones fronterizas colombianas es un factor fundamental en la migración transfronteriza. Los desplazamientos se derivan de factores políticos y sociales.

- Los desplazamientos forzosos de las poblaciones colombianas debido a la violencia y el narcotráfico dan origen a situaciones de vulnerabilidad y riesgo que no se encuentran en otros contextos fronterizos.

\section{Los puntos críticos de la frontera}

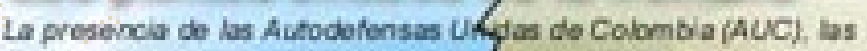

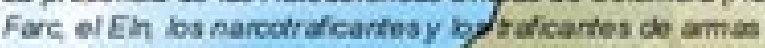

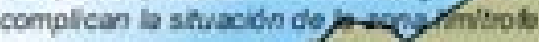

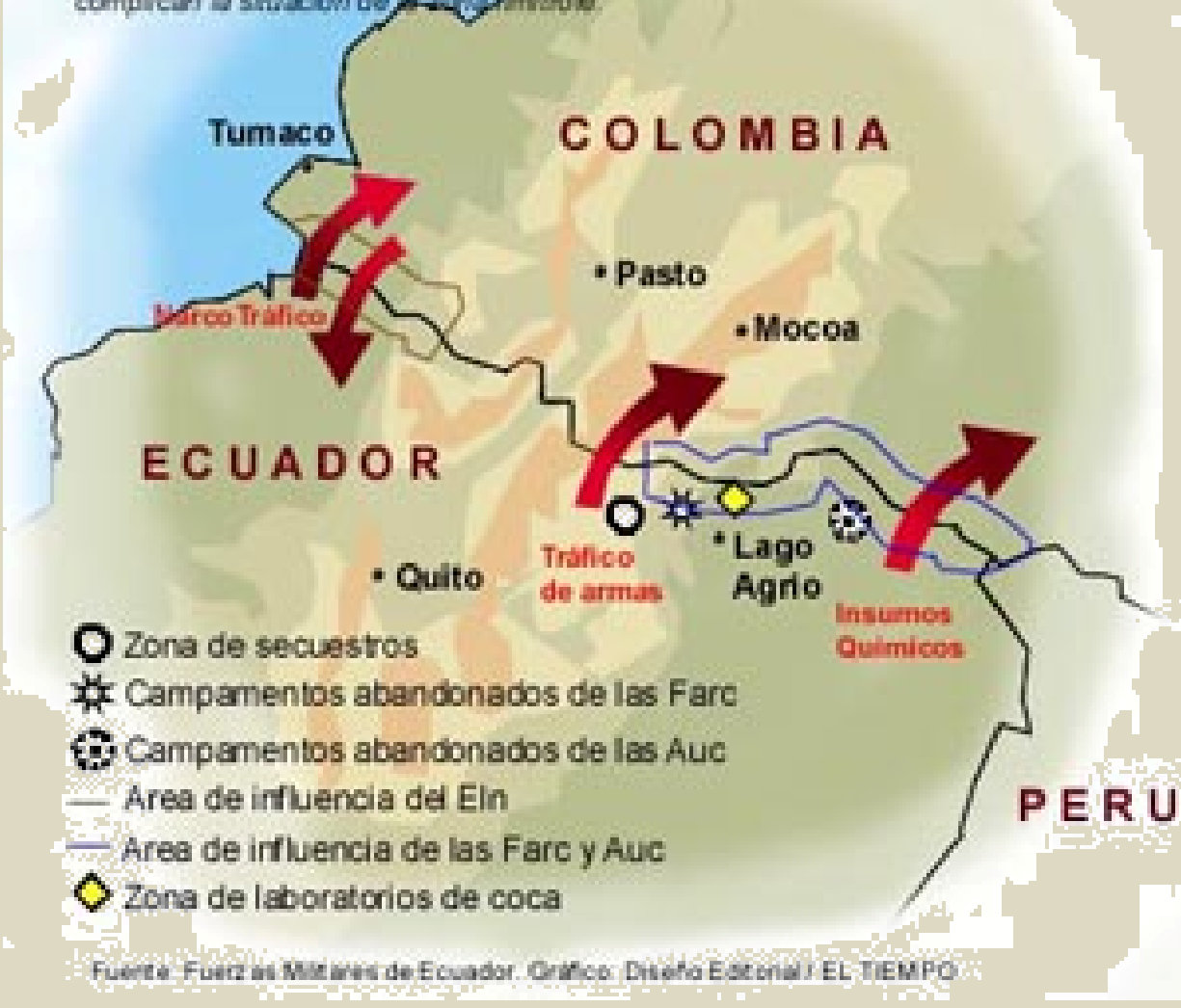

Fuente: Imagen obtenida de los puntos críticos de la frontera. S/f. 


\section{Estudio de caso $n^{\circ} 4:$ La "Triple Frontera" entre Argentina, Paraguay y Brasil}

\section{Zona de $2.500 \mathrm{~km}^{2}$ de extensión, enmarcada por los ríos Paraná e Iguazú}

- Tres ciudades importantes: Ciudad del Este (Paraguay), Foz de Iguazú (Brasil) y Puerto Iguazú (Argentina).

- Población superior al medio millón de personas entre las tres ciudades.

- Fuerte dinámica comercial y turística.

- Crisol de nacionalidades.

- Migración pendular.

- Trata de personas.

- Narcotráfico.

- Lavado de dinero.

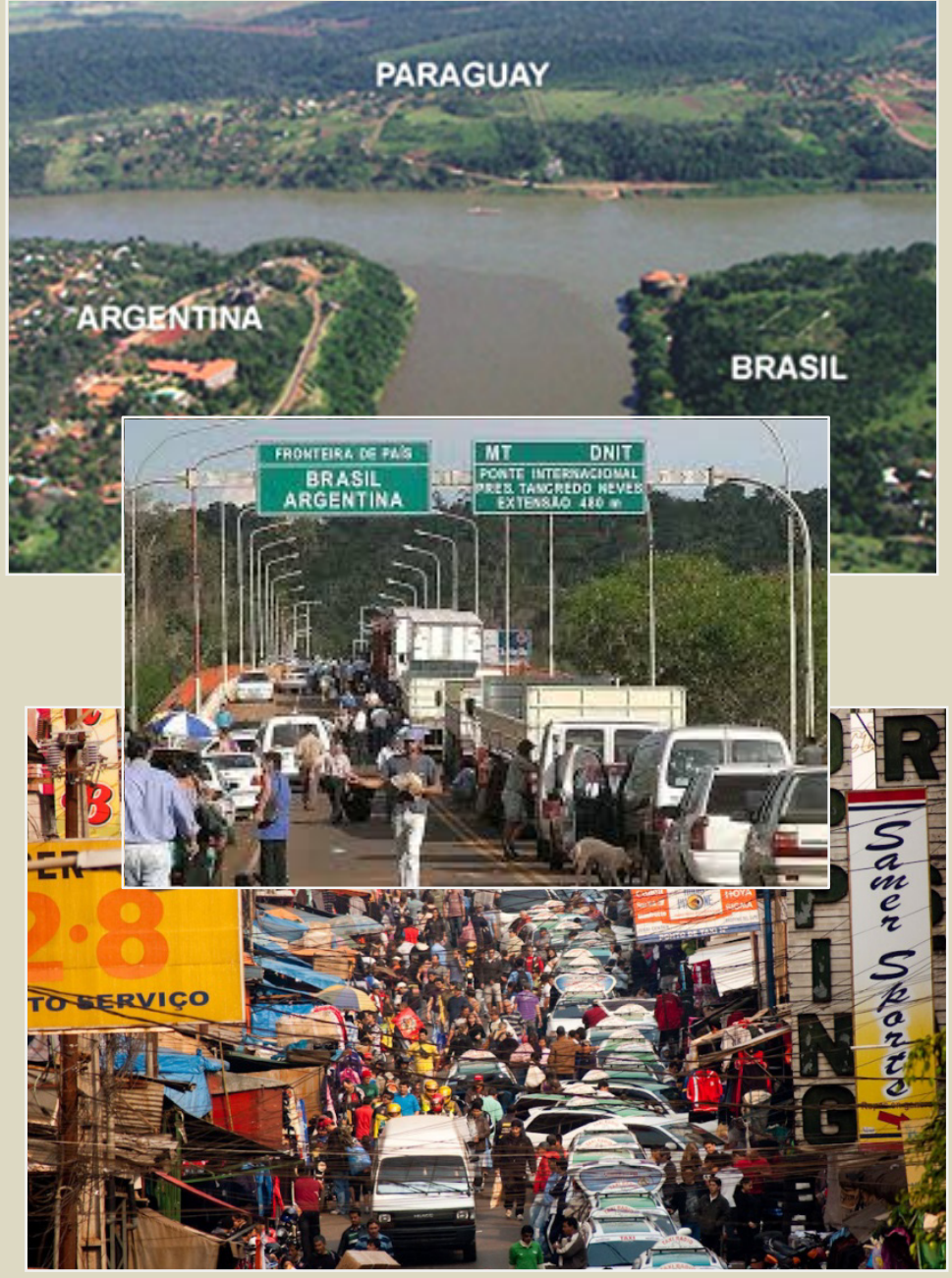




\section{BIBLIOGRAFÍA CONSULTADA}

- $\quad$ Barajas, Rosío (1989) "Complejos industriales en el sur de Estados Unidos y su relación con la distribución espacial y el crecimiento de los centros maquiladores en el norte de México", en Las maquiladoras: ajuste estructural y desarrollo regional, El Colegio de la Frontera Norte/Fundación Friedrich Ebert, México.

- Cardozo, Efraím (2007) "La Guerra del Chaco (Paraguay - Bolivia)". En: Breve historia del Paraguay. Cardozo, Efraím. Editorial Servilibro, AsunciónParaguay. Publicado en: Portal Guaraní. Disponible en Internet: www.portalguarani.com/586_efraim_cardozo/9705_la_guerra_del_chaco_paraguay_bolivia_por_efraim_cardozo.html

- CEPAL/CELADE (1999) “Migración y desarrollo en América del Norte y Centroamérica: una visión sintética”. Centro Latinoamericano y Caribeño de Demografía. Santiago de Chile, agosto de 1999. Disponible en Internet: http://archivo.cepal.org/pdfs/1999/S9980540.pdf

- de la O Martínez, María Eugenia. (2006) “Geografía del trabajo femenino en las maquiladoras de México”. Papeles de población, 12(49), 91-126. Recuperado en 08 de mayo de 2017, de http://www.scielo.org.mx/scielo.php?script=sci_arttext\&pid=S1405-74252006000300005\&Ing=es\&tIng=es.

- $\quad$ Diario Norte (2016) “Triple Frontera: turismo de naturaleza, diversión y compras libres de impuestos”. En: Diario Norte edición online. 28 de febrero de 2016. Disponible en Internet: http://www.diarionorte.com/article/134551/triple-frontera-turismo-de-naturaleza-diversion-y-compras-libres-deimpuestos

- $\quad$ El Rincón Universitario. S/f. “Guerra del Pacífico". Disponible en Internet: http://www.e-mas.co.cl/categorias/historia/guerrdelpaci.htm

- $\quad$ Espada, Blanca. S/f. “Guerra de Secesión”. En: SOBREHISTORIA.COM. Disponible en Internet: http://sobrehistoria.com/guerra-de-secesion/

- $\quad$ Fenix Davila, Donkan. S/f. “Posición geoestratégica de Venezuela”. En: Monografía.com. Disponible en Internet: http://www.monografias.com/trabajos82/posicion-geoestrategica-venezuela/posicion-geoestrategica-venezuela2.shtml

- $\quad$ Llácer Riaño, Rafael (2014) “Efemérides de Junio. 15 de junio de 1932. La Guerra del Chaco”. En: FILOSTAMP. 15 de junio de 2014 Disponible en Internet: https://filostamp.files.wordpress.com/2014/06/img648.jpg

- $\quad$ Historia Alternativa. S/f. “United Fruit Company (URSSEA)”. Disponible en Internet http://es.althistory.wikia.com/wiki/United_Fruit_Company_(URSSEA)

- Historia y biografías. S/f. “Guerra del Chaco Bolivia Paraguay. Causas del conflicto". Historia. Disponible en Internet: http://historiaybiografias.com/guerra_chaco

- Hjorth Boisen, Susann Vallentin (2009) “La industria maquiladora y la migración interna en México”. Gaceta Laboral , 15(1), 5-28. Recuperado en 08 de mayo de 2017, de http://www.scielo.org.ve/scielo.php?script=sci_arttext\&pid=S1315-85972009000100001\&lng=es\&tlng=es.

- $\quad$ Hypérbole (2015) “Lindes y fronteras". En: Hypérbole. Intersecciones creativas. 9 de noviembre de 2015. En. Disponible en Internet: http://hyperbole.es/2015/11/lindes-y-fronteras/ 
- $\quad$ Katty Nicole (2014) “Tratado de Ancon y consecuencias de la Guerra del Pacífico". En: Slideshare. I8 de julio de 2014. Disponible en Internet: http://es.slideshare.net/kattynicolarratiavilca/tratado-de-ancon

- $\quad$ “La expansión de los Estados Unidos. Guerra de Secesión 1861- 65”. 2013. En: Blog de WordPress.com. Disponible en Internet: https://laexpansionunitedstates.wordpress.com/guerra-de-secesion/

- $\quad$ Macadam, Davies (2010) "United Fruit Company". En. The Oligarch Company. 27 de mayo de 2010. Disponible en Internet: https://theoligarchkings.wordpress.com/2010/05/27/united-fruit-company/

- Milia, Juan Guillermo (2014) “La Triple Frontera y el terrorismo islámico”. En: Los Andes online. 19 de diciembre de 2014. Disponible en Internet: http://www.losandes.com.ar/noticia/la-triple-frontera-y-el-terrorismo-islamico

- Morales, Abelardo; Acuña, Guillermo; Li Wing-Ching, Karina (2010). “Migración y salud en zonas fronterizas: Colombia y el Ecuador”. En: Serie Población y Desarrollo 92. Centro Latinoamericano y Caribeño de Demografía (CELADE) - División de Población de la CEPAL. Disponible en Internet: http://archivo.cepal.org/pdfs/2010/S1000583.pdf

- Pueblos en camino (2015) "Conflicto Colombia-Venezuela: Despojo y exterminio indígena para el extractivismo transnacional”. 9 de octubre de 2015. Disponible en Internet: http://pueblosencamino.org/?p=1822

- $\quad$ Reliefweb (2001). “Los puntos críticos de la frontera”. 13 de abril de 2001. En: Reliefweb. Disponible en Internet: http://reliefweb.int/map/colombia/los-puntos-criticos-de-la-frontera.

- $\quad$ Rey Balmaceda, Raúl y Graciela De Marco (1992). "Conformación del sistema político territorial". Roccatagliata, Juan (coord.) 2da.ed. La Argentina. Geografía general y los marcos regionales. Buenos Aires, Planeta, 25-70.

- $\quad$ Rey Balmaceda, Raúl (1979) “Límites y fronteras de la República Argentina” Buenos Aires, Oikos. 15-50.

- Significance of The History Of The Standard Oil Company. S/f. Disponible en Internet: http://sigofthotsoc.weebly.com/

- Taringa (2013). “La polémica frontera entre USA y México en 40 imágenes". 2013. En: Taringa. 12 de mayo de 2013. Disponible en Internet: https://www.taringa.net/post/imagenes/16714241/La-polemica-frontera-entre-USA-y-Mexico-en-40-imagenes.html

- Wikipedia.com. S/f. Consecuencias de la guerra del Pacífico. Disponible en Internet: https://es.wikipedia.org/wiki/Consecuencias_de_la_Guerra_del_Pac\%C3\%ADfico

- Wikipedia.com. S/f. Frontera entre Colombia y Venezuela. Disponible en Internet: https://es.wikipedia.org/wiki/Frontera_entre_Colombia_y_Venezuela\#/media/File:Mapa_de_la_frontera_Colombia-Venezuela.svg

- Wikipedia.com. S/f. Triple Frontera. Disponible en Internet: https://es.wikipedia.org/wiki/Triple_Frontera

- Wikipedia.com. S/f. United Fruit Company. Disponible en Internet: https://es.wikipedia.org/wiki/United_Fruit_Company 


\section{Videos recomendados para la temática:}

- ¿Cuánto sabemos de la Guerra del Chaco? Un día como hoy empezó en 1932. Publicado el 9 sept. 2014 / La Guerra del Chaco, entre Paraguay y Bolivia, se libró desde el 9 de septiembre del año 1932. ¿Qué sabemos los bolivianos de esta guerra? https://www.youtube.com/watch?v=H3gMZKRHRIw

- Documental sobre la Guerra Del Pacífico. Publicado el 1 abr. 2013. https://www.youtube.com/watch?v=rN_l-rphgWs

- La industria maquiladora, evolución y situación actual (ponencia). Publicado el 06 Noviembre 2008 http://www.youtube.com/watch?v=C1e3glOPda4

\section{Películas recomendadas para la temática:}

- Gangs of New York - titulada Pandillas de Nueva York en Hispanoamérica- es una película histórica del año 2002 dirigida por Martin Scorsese y escrita por Jay Cocks, Steven Zaillian y Kenneth Lonergan. Ambientada durante la mitad del siglo XIX en el barrio de Five Points de Nueva York, la película está en parte inspirada en el libro The Gangs of New York (1928) de Herbert Asbury.

- Far and Away - titulada Un horizonte muy lejano en Hispanoamérica. Película de aventuras que trata el tema de la conquista de territorios en América del Norte a comienzos del siglo XX, protagonizado por Tom Cruise y Nicole Kidman, llevada al cine en 1992. 